\title{
Do consumers borrow on their cheapest credit card? Evidence from Mexico*
}

\author{
Alejandro Ponce ${ }^{\dagger}$ \\ Stanford University
}

\author{
Enrique Seira \\ SHCP, Mexico
}

\author{
Guillermo Zamarripa \\ SHCP, Mexico
}

July 7,2008

\begin{abstract}
Most cardholders have more than one credit card, yet, it is not evident how these individuals manage their accounts. In this paper we construct a novel data set that includes information on all the credit cards held by more than 10,000 consumers in Mexico in 2004 and 2005 and empirically study the intra-temporal allocation of debt, payments and purchases among the credit cards consumers already hold. We find that the difference in the interest rates between homogeneous cards is not an important determinant of allocations. On average, cardholders forego potential savings for a sum that amounts to $16 \%$ of their financing cost. We show that non-price determinants of allocations have more explanatory power than interest rates. We find that consumers tend to put a larger fraction of their monthly payments and purchases on the card they spent more on during the preceding billing period, regardless of their interest rate ranking. We explore potential explanations for these findings including unawareness of the interest rates, small stakes, mental accounting and financial unsophistication. Although we cannot fully disregard some hypotheses, the most compelling explanation relates to mental accounting and financial unsophistication. The low price sensitivity can explain why high interest rates prevail in this market, regardless of any search or switching cost. From a policy perspective, our conclusions suggest that financial education could enhance competition in credit card markets
\end{abstract}

KEYWORDS: Credit cards; household finance; debt heuristics; consumer behavior; Mexico.

\footnotetext{
${ }^{*}$ We are grateful to Jon Levin, for numerous discussions, revisions and comments. We thank Susan Athey, Tim Bresnahan, Liran Einav, Soohyung Lee, Pedro Miranda, Sriniketh Nagavarapu, Roger Noll, Felix Reichling, Joanne Yoong and participants at Stanford University IO and the World Bank seminars for suggestions. Ponce and Seira acknowledge the support of the Dissertation Grant of the Federal Reserve Bank of Boston's Research Center on Behavioral Economics and Decision-Making. Ponce appreciates the support of the Kohlhagen Fellowship Fund at Stanford University and Mexico's National Council for Science and Technology (CONACYT). All errors remain our own.

${ }^{\dagger}$ Corresponding author: Department of Economics, Stanford University, Landau Economics, Stanford, CA 94305. E-mail: aponcer@stanfordalumni.org, aponcer@gmail.com
} 


\section{Introduction}

Lack of competition is an often mentioned problem in the credit card industry. According to the literature, adverse selection and the existence of consumers with biased beliefs about their future indebtedness allow credit card issuers to charge high interest rates and therefore, obtain higher profits [Ausubel (1991)]. In this paper we do not contend this explanation, but provide evidence of another feature that could hinder competition too, i.e. the fact that many individuals do not pay attention to interest rates when allocating debt among their credit cards.

Credit cards are the most popular source of consumer credit. In fact, most individuals hold not only one, but many of them. Yet, there are no studies examining how people with multiple credit cards manage these accounts. In this paper, we fill this gap by investigating empirically how consumers with several credit cards allocate their debt, payments and purchases among them. Our primary interest is to assess the extent to which interest rates influence individuals' decisions regarding which credit card to borrow on. The theory behind this decision is simple. Almost any model of consumer choice predicts that in the presence of perfect information and homogeneous goods, individuals should borrow primarily on the credit card with the lowest interest rate. More specifically, if individuals are aware of the difference in prices, credit cards are homogeneous in all relevant respects except for the interest rates, and consumers are not constrained by the contractual features of their cards (e.g. credit limits and minimum payments), we should observe individuals allocating their debt, if any, to the card with the lowest interest rate. Alternatively, if consumers are unsophisticated, have biased preferences, are poorly informed, or have to perform costly calculations, they could make their financial decision randomly or on the basis of factors other than prices. This view is related to the idea of financial unsophistication [Bernheim and Garrett (2003)], unawareness, and mental accounting [Thaler (1985), Thaler (1999), Prelec and Loewenstein (1998) and Ranyard, Hinkley, Williamson and McHugh (2006)]. Regardless of the reasons, the point is that borrowers could make their allocation decisions using different criteria than monetary costs. It is an empirical question to assess how prevalent these behaviors are in the real world.

We investigate which factors, including interest rate differentials, have a significant influence on the fraction of debt, payments, and purchases that consumers allocate to a certain card. In particular, we concentrate on the intra-temporal allocation across cards and take the total monthly levels of debt, purchases, and payments as given. This is to simplify our analysis at little cost, as dynamics seems to play a minor role on the way consumers manage their debt among their different cards. ${ }^{1}$ More specifically, there are three cases in which dynamics may influence which

\footnotetext{
${ }^{1}$ Conceptually, we can separate the consumer's decision problem into two stages: In the first stage, for each period, consumers select the total amount of purchases and payments to be made with their credit cards on that month, and as a result, the total amount of debt to carry on. In the second stage, once individuals have selected the totals, they decide on the allocation of those purchases and repayments between the cards they already hold.
} 
card consumers select to borrow on: Non-divisible purchases, low realizations of the income stream, and anticipated changes in the credit limit. For example, consumers may pay off their cheap credit card to free-up credit for a large purchase, or they may borrow from expensive credit cards today because they believe they will be able to pay the debt back in the future, although ex-post, they may not be able to do so [Ausubel (1991)]. Alternatively, if banks consider borrowing in a nonlinear way when deciding to boost a credit line, consumers could anticipate such rule and borrow in all their credit cards, regardless of the interest rates, in order to relax their liquidity constraints in the future. Despite these concerns, we believe these considerations are quantitatively small. First, about $70 \%$ of the credit card purchases in Mexico are groceries, which are highly divisible. Second, we find that the allocation of purchases and payments are highly persistent over time. Finally, survey data suggest that consumers have a very vague idea regarding how banks assign credit limits.

Our empirical analysis exploits the variation provided by the difference in the interest rate across comparable credit cards already held by each consumer. This difference is, on average, 1.1\% per month. Although interest rates are set by the product, there is substantial cross section and time series variation available. More specifically, there are three reasons why consumers could have credit cards with different interest rates in a given period. First, consumers may simply have chosen two cards with different interest rates. Second, the 'effective' interest rate of a given card could be lower because the bank granted the rebate as a complementary service when opening a checking or saving account or because the borrower performs well during the lifetime of the card. Third, the bank could send a temporary low interest rate offer. The cross section and time series variation in the difference in the interest rates allows us to identify whether consumers pay attention to these differentials when allocating their monthly payments and purchases. For simplicity, our main analysis focuses on individuals with two credit cards whose credit cards have a similar reward structure.

Our research looks mainly at the allocation of payments and purchases, rather than the allocation of debt. This is because, by focusing on flows rather than stocks, we are able to control for liquidity constraints and balance transfer costs. ${ }^{2}$ In addition, by looking at immediate choices, we are in better shape to unravel specific decision rules than we would be if studying a state variable such as debt. Finally, throughout our analysis, we control for factors such as credit limits and minimum monthly payments that could influence consumers' allocation decisions.

In order to properly study allocation decisions, we require a panel of high-quality data with

\footnotetext{
${ }^{2}$ Transferring balances in Mexico could be particularly expensive. Before 2004, balance transfers were not allowed. In January 2004, the Central Bank of Mexico issued a new law mandating commercial banks to allow consumers to transfer balances from other credit cards [Ley para la Transparencia y el Ordenamiento de los Servicios Financieros (2004)]. Nonetheless, despite the high expectations raised by this law, balance transfers are not frequent, and interest rates have reportedly not changed.
} 
information on all the credit cards held by each consumer. We constructed such data set with the collaboration of the Credit Bureau and the three largest commercial banks in Mexico. First, we solicited the Credit Bureau to draw a random sample of 100,000 consumers who had at least one credit card by November 2004. Then, the Ministry of Finance of the Mexican Government asked to the three largest banks to provide monthly information for each one of the accounts in the sample. The result is a proprietary novel data set that enables us to link consumers with most of their monthly credit card information, provided that the credit cards were issued by one of the three cooperative banks. Since the industry is highly concentrated, by using information from these three banks, we were able to match the entire credit card activity of $69 \%$ of the card holders in our original sample. ${ }^{3}$ The data are of very high quality, containing the Credit Bureau reports as well as the entire credit card records observed by our three banks, including monthly debt, purchases, cash advances, payments, interest rates, credit limits, and socio-demographic characteristics during part of 2004 and 2005.

We find that the difference in the interest rate between consumers' credit cards is a very poor predictor of how individuals allocate their debt, purchases and payments between accounts. Among individuals borrowing on credit cards, half of them borrow on their more expensive card. Regressions of the share of debt on the difference in the interest rates are able to explain less than $0.06 \%$ of the variation. These results also hold when we study the allocation of purchases and payments, and control for the contractual features of credit cards, namely credit limits and minimum payments. We conclude that individuals do not borrow on their cheaper card despite it could be feasible for them to do so. On average, these cardholders forego potential savings for a sum that amounts to $16 \%$ of their financing cost.

When we study other possible factors that influence allocations, we find that consumers tend to put a larger fraction of their monthly (excess) payments and purchases on the card they spent more on during the preceding period, regardless of its price. Although there is much heterogeneity in this decision, this result suggests that there is significant inertia once a card is chosen. This is consistent with the so-called "front of the wallet" behavior, which is regularly mentioned in the credit card jargon. This fraction however, is smaller when consumers make either large payments or large purchases; in these cases, factors such as the identity of the card with more debt or idiosyncratic features of each plastic also matter. These results are robust to alternative samples designed to exclude observations with small differences in interest rates, distinct billing cycles or small levels of debt. We explore potential explanations for these findings including unawareness of the interest rates, small stakes, mental accounting/financial unsophistication. Overall, our results are difficult to reconcile with the standard cost minimizing framework. Although we cannot fully disregard

\footnotetext{
${ }^{3}$ In recent years, the three largest banks have concentrated about $80 \%$ of the market in terms of number of accounts and total debt levels.
} 
some hypotheses, the most compelling explanation to our results relates to mental accounting and financial unsophistication.

To our knowledge, this is the first paper to present field evidence on how consumers periodically allocate their debt among the financial instruments available to them. While previous literature has looked at consumers' departure from standard utility maximization, it is fair to say that most studies have focused on inter-temporal decisions and biased expectations about future preferences and future consumption [Miravete (2003), Agarwal, Chomsisengphet, Liu and Souleles (2005), Shui and Ausubel (2005) and DellaVigna and Malmendier (2006)]. Our analysis departs from these studies by focusing on 'intra-temporal' instead of 'inter-temporal' decisions. As a result, our analysis does not involve any uncertainty, allowing us to be agnostic about the form of the utility function and time varying shocks. The closest analysis to ours is Benartzi and Thaler (2001), who show that consumers use naive diversification strategies and divide their contribution evenly across the funds offered in their saving plans. Our paper complements their work in at least three ways. First, we study consumers' allocation of short term liabilities instead of long term assets. Second, in our setting, consumers make decisions every month and not just once, thus increasing the scope for learning [Agarwal, Driscoll, Gabaix and Laibson (2008)]. Third, it is likely that the complexity and uncertainty of our environment is lower, as the planning horizons are shorter.

Overall, our paper contributes to the literature and policy debate in three ways. First, we add to the household finance literature by documenting the relationship between prices and borrowing on credit cards [Campbell (2006)]. Second, we contribute to the so-called "credit card puzzle" debate. Several papers have argued that the fact that consumers borrow high and lend low at the same time represents a puzzle for the neoclassical models of consumer choice [Gross and Souleles (2002) and Bertaut and Haliassos (2006)]. ${ }^{4}$ Here, we address a similar problem but in a simpler setting and find that consumers in fact, leave money on the table. Finally, the paper adds to the behavioral literature on heuristics and market outcomes [Ellison (forthcoming)]. From a policy perspective, our analysis is relevant for at least two reasons. First, not paying attention to interest rates can be quite costly for consumers. Second, if individuals allocate their debt based on rules other than interest rates, high and disperse prices could prevail in the market even without switching or search costs. This argument could explain why the effect of the law that allowed consumers to transfer balances in Mexico was limited.

The remainder of the paper is organized as follows. In Section 2, we present a description of the Mexican credit card industry. In Section 3, we introduce the data used in our analysis. Section 4 shows descriptive evidence on how consumers allocate their credit card debt, payments and purchases. Section 5 explores the determinants of allocations. In Section 6, we explore possible

\footnotetext{
${ }^{4}$ Zinman (2007) disagrees with this literature by arguing that credit card debt is not a close substitute for cash. His critique does not apply here though, as we study arbitrage across homogeneous cards differing only by the interest rates
} 
explanations for the results. Section 7 analyzes some of the supply side implications. Section 8 concludes.

\section{Credit cards in Mexico}

\subsection{The credit card industry in Mexico}

As of December 2005, 12.2 million credit cards were active in Mexico. The value of transactions equaled 185 billion pesos and the outstanding balances on revolving accounts surpassed 148 billion pesos up from 47 billion in 2002. Among consumers who had at least one credit card in December 2005, 61\% carried more than one. This is consistent with a small fraction of people having access to this market. For example, the number of credit cards per individual in working age has ranged between 0.19 and 0.28 over these years, and the number of households with access to at least one credit card has barely reached $5 \%$ of the population. ${ }^{5}$

The credit card market in Mexico is highly concentrated. Three national banks have consistently controlled more than $80 \%$ of the market during the last five years. The average credit card has had an associated interest rate which has been 28 percentage points above the federal discount rate [Banxico (2006)] and fees and service charges have been ranked as the highest in Latin America [Avalos and Hernandez (2006)].

During all this time, the credit card business has operated without ceilings on interest rates and fees. Most regulation has focused on the disclosure of information to consumers at the time of contracting. In recent years though, regulation to improve the competitive environment of the industry has been enacted. In January 2004, the Central Bank of Mexico issued a new law mandating commercial banks to allow consumers to transfer balances from other credit cards. ${ }^{6}$ The introduction of balance transfers has allowed banks, particularly entrants, to compete with low interest rate products. Nonetheless, despite the expectations raised by this law, interest rates on most cards are still high, balance transfers are reportedly rare and consumers still use the cards with higher interest rates.

\subsection{The credit card contract}

In Mexico, a typical credit card contract specifies the credit limit, the applicable fees, the benefits of the card, as well as the rules on how to compute the minimum payment and the finance charge on the outstanding balance. With the exception of the credit limit, all terms are set by

\footnotetext{
${ }^{5}$ The average Peso-Dollar exchange rate for December 2005 was 10.62 . This rate fluctuated between 11.42 pesos per dollar in January 2005 and 10.54 in January 2006. Source: Banco de Mexico (http://www.banxico.org.mx/PortalesEspecializados/tiposCambio/indicadores.html)

${ }^{6}$ Ley para la Transparencia y el Ordenamiento de los Servicios Financieros (2004)
} 
the product, not the consumer. Cards differ from each other by the benefits they offer, by nonpecuniary features, by the fees and service charges, and by the interest rate (or more specifically, by the margin over the Prime Rate).

The credit card activity is organized around the monthly billing cycle. Each month the cardholder receives an account statement specifying the purchases, cash advances and payments made during the previous cycle. The statement also includes the fees and interest accrued during the period as well as the minimum payment due and current interest rate.

Figure 1 illustrates a typical billing cycle. This figure includes nearly all variables we will use in the analysis. Most variables are determined during the billing cycle, but observed at the end of the period. The exceptions are the Minimum Monthly Payment $P M_{i n} n_{t+1}$ and the closing balances $B_{t}$, which are determined at the end of the cycle. During the billing cycle, the card holder can use the card for purchases or cash advances $X_{t}$ up to the credit limit $L_{t}$ assigned previously by the bank. If the credit limit is surpassed, an overlimit fee is charged. The cardholder can use up to $20 \%$ above the credit limit; beyond this point, the card is blocked.

Throughout the paper, we use the Average Daily Balances (ADB) as the key variable to measure interest-incurring debt. For a given period $t$, this variable is labeled $D_{t}$. The ADB are calculated by the bank by taking the daily balance on each day of the period, including current purchases and cash advances, minus any payments received, divided by the number of days in the cycle. The accrued interest is calculated by multiplying a pre-specified interest rate times the ADB in a given period. The card holder has a grace period of 20 days, counting from the closing date of the previous cycle, to make the minimum payment. This way, most monthly payments $P_{t}$ correspond to those payments made to pay back the ending balance of the previous period $B_{t-1}$ (or at least the associated Minimum Monthly Payment $P \mathrm{Min}_{t}$ ). If the card holder pays the closing balance $B_{t-1}$ in full, the ADB equal zero and no interest is accrued during the month. If the cardholder makes at least the minimum payment but does not pay the balance in full, the ADB are positive and an interest is accrued. If the cardholder fails to make even the minimum payment, the issuer charges a late payment fee of $\$ 230$ pesos and extra interest, and the card is blocked until the time the payment is received.

\section{Data}

\subsection{The data set}

We constructed a novel panel date set of credit card usage in Mexico. The data collection involved the collaboration of the Credit Bureau and the three largest commercial banks in Mexico. The result is a unique proprietary data set that enables us to link consumers with all their credit card information. Our data contain the Credit Bureau reports as well as the entire credit card records 
observed by these three banks, including monthly balances, purchases, cash advances, payments, interest rates and socio-demographic characteristics during part of 2004 and 2005.

To construct the data set, we asked the Credit Bureau to draw a random sample of 100,000 consumers who had at least one credit card by November 2004. This data set contains a unique identifier for each individual, all the account numbers for each one of them, the delinquency status of these accounts as well as some socio-demographic characteristics. Then, with the account identifiers at hand, the Ministry of Finance of the Mexican government asked the three largest banks to provide monthly information for every account in the sample. This data set comprises all the information listed on the accounts' monthly billing statements, including debt, purchases, cash advances, payments, minimum payments, credit limits and interest rates. The data also contain information about the 'type' of card (e.g. Classic, Gold, Platinum, etc.) and some additional demographics recorded at the time of solicitation. Jointly, the two data sets allow us to follow, for each individual, the monthly changes in most credit card accounts.

Due to the administrative costs involved in acquiring the data, we focused only on the three largest banks. This is not a problem for our analysis, though. Since the industry is highly concentrated, we were able to match the entire credit card activity of $69 \%$ of the card holders in our original sample. The data cover the period 2004-2005 for two banks, and from October 2004

to September 2005 for the third one. Finally, to ensure confidentiality, all the information was provided in such a way that it is impossible to infer the identity of the account holders.

\subsection{Sample construction}

For the sake of simplicity, we focus on individuals holding 'exactly' two 'comparable' credit cards issued by one of our three banks. Moreover, we only consider individuals whose credit cards remained 'active' during the entire sample period.

We define two credit cards as 'comparable' if their non-price attributes are similar. More specifically, we characterize two cards as 'comparable' if both cards are of the same 'type' (e.g. both cards are Gold) or if they have the same rewards programs. In general, cards of the same type but issued by different banks share the same rewards structure. There is little variation in the types of card held by most consumers; for example, around $65 \%$ of the cards are labeled as 'Classic'.

We focus only on cards that remained 'active' during the entire sample period. More specifically, since our interest is not in the opening and closing behavior, we concentrate on consumers who kept both of their cards open between January 1, 2004 and December 31, 2005. In addition, we removed all the store cards (e.g. Wal-Mart Card) from the sample, as these cards can only be used in specific businesses and therefore are not good substitutes for the credit cards issued by banks. We also eliminated individuals who had less than six months of information in any of the variables 
required for our analysis. Finally, due to administrative and technical issues while extracting the information, one of the banks provided data starting in late 2004, so our panel is unbalanced. This leaves us with a sample of 114,720 consumer-months. Out of these observations though, debt is positive only for 103,343 consumer-months. It is only for these observations that the problem of which card to borrow from is really relevant. Therefore, our final sample contains 10,335 consumers and 103,343 consumer-months. The median number of periods by consumer in our final sample is 11 , and the 95 th percentile is 16 .

We select the sample this way to simplify the allocation problem and to have a clean comparison between homogeneous cards. Although useful, this selection precludes us from generalizing our results to the entire population of credit card holders. We acknowledge this limitation but point out two facts. First, approximately $17 \%$ of card holders in Mexico had exactly two active credit cards as of December 2005, making our analysis directly relevant for this population. ${ }^{7}$ Second, there is no obvious reason why individuals with two cards allocate their debt less optimally than consumers with three or more cards. In fact, it is quite possible that individuals with more credit cards leave more money on the table. This could happen for two reasons. First, stylized models of attention would predict that the more cards individuals hold, the more complex their decision processes are, and therefore, the more likely is that they rely on heuristics. Second, it is likely that some consumers choose to hold more cards simply because they demand more credit and thus, take more debt, making mistakes more costly. Still, it is possible that individuals who have more cards also earn higher incomes, which could imply that they may not worry about borrowing from more expensive cards. We address these concerns later on by extending the sample to include individuals who own more than two cards. Nonetheless, we believe that overall, the benefits of focusing on those consumers with two cards more than compensate the costs.

\subsection{Interest Rate differences}

We exploit the variation provided by the difference in the interest rate across the credit cards already held by each consumer. In Mexico, interest rates are set by the product. Yet, there are three reasons why, in a given month, individuals may hold two cards with different interest rates. First, consumers may have simply chosen credit cards with different interest rates. Second, the interest rate in a given card could be lower because the bank granted a rebate as a complementary service for opening a checking or saving account or because borrowers have performed well during the lifetime of the card. Third, the bank could send a temporary reduction in the interest rate or teaser rate offer. These offers are targeted by banks to existing cardholders with a duration ranging from one to six months. Teaser rate offers are widespread in Mexico: in 2005, the average credit

\footnotetext{
${ }^{7}$ In the original random sample derived from the Credit Bureau, 39\% of consumers had one active credit card, $17 \%$ had two active credit cards, $10 \%$ had three credit cards, while $34 \%$ had more than three
} 
card had an active TRO for approximately 2.1 months.

The interest rate differences are quite significant. Figure 2 shows the distribution of the monthly interest rate differential among consumers' credit cards. The distribution has three modes and substantial variation. The median difference is $1.2 \%$, and the overall standard deviation is $1.18 \%$ points. As expected, there is substantial variation within and among consumers. The standard deviations within consumers and between consumers are $0.77 \%$ and $0.92 \%$, respectively.

\subsection{Descriptive statistics}

Table 1 presents summary statistics for the main variables we will use in our analysis. The top panel shows the mean of the variables that appear in the cardholder's balance statement once we combine the two credit cards held by each individual. Here, the unit of analysis is a consumermonth. Some facts stand out. First, the amount of interest paying debt is non-negligible. The average total debt equals $\$ 22,136$ pesos, which corresponds to more than two times the median monthly income of the consumers in our sample. As a matter of fact, consumers use their credit lines extensively. The average utilization rate of the combined cards is $61 \%$. Interestingly, consumers borrow on their credit cards even though the average monthly debt-weighted interest rate equals $2.54 \%$. Second, most of the time, consumers pay interest and $42 \%$ of the time, individuals are charged a late payment or an overlimit fee. Finally, out of the consumers who borrow, $82 \%$ allocates their debt in both cards.

Monthly statistics can mask substantial cross-time heterogeneity for a given consumer. Panel B in Table 1 displays some summary statistics at the consumer level, that is, once we take the average across-months for each individual. Yet the picture looks quite similar. About $90 \%$ of consumers are charged interest half the time (in fact, $77 \%$ of consumers in our sample always incur interest). Similarly, $74 \%$ of consumers borrows in both cards at least half of the time. Taken together, these figures suggest that consumers in our sample seem to be heavily indebted and usually borrow in both cards.

The bottom panel presents some demographics. This information comes from the credit bureau reports or from the banks' records at the time of origination. Unfortunately, banks do not keep these records for long periods; consequently, the number of observations varies greatly. We deflate the monthly income using the Banco de Mexico consumer price index. The median monthly income in our data is $\$ 10,000$ pesos. The average age is 44 years while the average tenure with the oldest credit card is 8 years. 


\section{Descriptive evidence on allocation mistakes}

\subsection{Debt Allocation}

In this section we study whether individuals minimize their interest cost. Given the features of our sample, we would expect individuals to borrow as much as possible on the credit card with the lower interest rate, conditional on avoiding overlimit fees. We start by analyzing how consumers allocate their debt among the credit cards they already hold, conditioning on their total credit card borrowing. There are two points deserving attention here. First, our focus is on how individuals pick which card to borrow from, among those available in their wallets. That is, we do not study how consumers decide which card to apply for, considering the available options in the market. Although relevant, this decision is made rarely and involves considerations such as the number of products available as well as search and switching costs. Instead, we focus on a simpler and recurrent decision, which allows us to abstract away from such factors and concentrate on the decision making process. Second, our focus is on the 'intra-temporal' instead of 'inter-temporal' decisions. That is, we do not study how much consumers borrow, or whether they borrow optimally given their intertemporal constraints and time preferences. Instead, for every period, we take consumers' credit card debt as given, and investigate which cards individuals choose to borrow from. There are advantages and disadvantages to conditioning on total borrowing and abstracting from dynamic considerations. The main advantage is that we are able to focus on a much simpler problem. The main concern is that allocation may depend on the expected income and expectations about changes in the credit card features. For example, consumers may borrow from expensive credit cards today because they believe they will be able to pay the debt back in the future, although ex-post, they may not be able to do it [Ausubel (1991)]. Alternatively, if banks consider borrowing in a non-linear way when deciding to boost a credit line, consumers could anticipate such rule and borrow in all their credit cards, regardless of the interest rates, in order to relax their liquidity constraints in the future. We will address these concerns later on, when we study the allocation of payments and purchases as well as the persistence of the allocation decisions.

We first look at the monthly allocation of debt across consumers' credit cards. The upper left panel of Figure 3 shows the histogram of the share of interest-paying debt allocated to the cheapest card. The unit of analysis here is a consumer-month. The distribution is quite symmetric. Most of the time, consumers borrow on both credit cards. In fact, $48 \%$ of the time, consumers hold more than fifty percent of debt on their more expensive credit card. A possible concern could be that the difference in the interest rate is very small for consumers to notice. To address this, the upper right panel of Figure 3 provides a histogram using only observations for which the difference in the monthly interest rate is larger than $0.5 \%$. Both figures are remarkably similar.

The previous figures do not take into account an important feature of credit card contracts, 
namely, the credit limit. This is important. For instance, if the credit limit of the cheaper credit card binds, it may be possible that consumers still make good decisions by borrowing on the card with a higher interest rate. To get a sense of the importance of the limit constraint, the lower right panel of Figure 3 presents the distribution that would arise if consumers allocate debt up to the credit limit on the cheaper card, and the rest on the more expensive one. The histogram looks quite different from the previous figures. The results from the nonparametric Mann-Whitney test indicate that the difference between these distributions is statistically significant. In general, optimality implies a large share of debt to be put in the cheaper card. However, the striking difference between the upper and lower panels certainly suggests that feasibility or credit limit constraints do not fully explain why consumers allocate debt to the more expensive cards.

\subsection{Allocation of payments, purchases and cash advances}

So far, we have concentrated on debt. The reason for this is that interest is charged on outstanding balances. Focusing on debt could be misleading when studying consumers' choices, though. Ultimately, individuals decide on purchases, cash advances and payments. Debt is simply the cumulative flow of these variables. Making this distinction is important. If consumers do follow heuristics, these are more likely to come out when analyzing the immediate decisions on purchases, cash advances and payments, and less so when exploring a state variable such as debt. Additionally, individuals could exhibit a different behavior when shopping at stores than when handling the credit card payments (e.g. as in accountant-shopper models [Bertaut and Haliassos (2001)]). Because of these reasons, from now on, we concentrate on the allocation of new purchases, cash advances and payments. This approach has two additional advantages. First, it allows us to avoid double counting one-time mistakes and abstracting from liquidity constraints considerations. More specifically, individuals could make a mistake on purchases, use an expensive card, and lack the money to pay off this debt afterward. This mistake would be carried forward as debt for many periods. Our approach allows us to evaluate this decision separately. On one hand, we are able to assess the allocation of purchases as a one-time mistake. On the other hand, we can study how individuals regularly allocate the monthly payments to pay off this debt, conditional on the total amount repaid to both cards. This way, we do not only avoid carrying mistakes forward, but also control implicitly for the liquidity constraints faced by each consumer. Second, this approach allows us to rule out balance transfer costs as an explanation for the observed allocation of debt. ${ }^{8}$ If consumers minimize their financing costs when they decide which card to use and which card to pay off, then it is very likely balance transfer costs explain the observed allocation of debt. If not, it is quite likely that the allocation of credit card debt is driven mainly by other factors.

\footnotetext{
${ }^{8}$ Balance transfer costs include not only the fees for transferring balances but more importantly, consumers' switching costs.
} 
We start by studying how individuals allocate the credit card monthly payments, conditional on the total amount repaid to both cards. The upper left panel of Figure 4 displays the distribution of the fraction of payments allocated to the more expensive credit card. The unit of analysis here is a consumer-month. For every period, the share of payments is defined as the sum repaid to the more expensive card, over the total amount repaid to both cards during that month. Here, we only consider those months in which consumers had debt outstanding on their two cards, as only for these months the allocation of payments is relevant for minimizing the interest accrued. The distribution is symmetric about 0.5 and fairly uniform, with three modes at zero, one half and one. The spikes at the extreme edges of the histogram represent primarily months in which consumers missed one of the monthly minimum payments. Interestingly, $45 \%$ of the time, consumers allocate less than half of their payments to the more expensive card. Once we include the 50/50 allocation, this number increases to $53 \%$.

Although informative, this distribution is difficult to interpret, as most consumers make at least the monthly minimum payment in order to avoid late payment fees. This is problematic, because the share allocated to pay off a given card could simply reflect the constraints imposed by the monthly minimum payment instead of the choices made by the cardholders. This problem is acuter if many consumers barely make the minimum payment. To fix ideas, Figure 6 describes all possible combinations of payments to the cheap and expensive cards. The dashed lines represent the minimum payments due on each card. The red line corresponds to the constraint required to avoid the late payment fees. To be more precise, if consumers' total payments locate to the right or along this line, it is feasible for individuals to make at least the minimum payment due on both cards. Area A corresponds to those allocations in which consumers make the minimum payment on both cards. Regions $\mathrm{B}$ and $\mathrm{C}$ stand for combinations in which individuals miss the minimum payment on one card despite it was feasible for them not to do so. On the contrary, areas D, E and $\mathrm{F}$ represent situations in which consumers can not avoid late payment fees, given the amount repaid to both cards. In parenthesis, we show the percentage of observations falling into each category. For $72 \%$ of observations, individuals make the minimum payment due on both cards and repay more than the minimum on at least one card. We will concentrate on these cases. This is to exclude situations in which individuals are constrained or miss the due date. Later on, we will incorporate these situations.

The upper right panel of Figure 4 plots the histogram of the fraction of "payments above the minimum' allocated to the more expensive card. This fraction is defined as the payment made to the more expensive card minus the minimum payment on that card, divided by the total payments made during that period minus the sum of the minimum payments on the two cards for that month. The pattern of the previous figure remains. The histogram is mostly uniform, with two spikes at zero and one. Here, the spikes stand for observations in which consumers only made the 
minimum payment due on one card and paid above the minimum on the other one. Only $24 \%$ of consumers allocates most of their payments to the more expensive card. The remaining $76 \%$ would save money by following a simple rule, that is, making the minimum payment on the cheaper card and allocating most repayments to the more expensive card.

Individuals may fail to pay off the more expensive card because the interest rate differential is small. To explore this point, the lower right panel of Figure 4 plots the kernel density of the fraction of 'payments above the minimum' allocated to the more expensive card, by terciles of the interest rate differential between consumers' cards. The distribution has the same shape regardless of this difference. In unreported regressions, we find that decile indicators of the interest rate differential explain only $0.04 \%$ of the variance in the share of payments in excess of the minimum. The results still hold when we restrict the sample to observations in which the monthly sum repaid to both cards exceeds $\$ 1,000$ or $\$ 2,000$ pesos. These findings suggest the allocation of monthly payments between cards is not driven by the difference in the interest rates between the credit cards consumers hold. We explore these issues further in the next section.

We now consider how consumers allocate their monthly purchases and cash advances, conditional on the purchases and cash advances undertaken with both cards in a given month. Although purchases and cash advances are not exactly equal, for simplicity we will treat them alike and sum them up. Therefore, hereafter, we will refer to purchases and cash advances as simply purchases. Studying the allocation of purchases presents more challenges than analyzing the allocation of payments. This is for two reasons. First, since banks usually put credit cards on hold (i.e. consumers are not able to use them) when individuals fail to make the minimum payment due, consumers who turn delinquent do not really have an allocation choice to make, as they cannot purchase with at least one credit card. Second, as cardholders may use their cards with the expectation to pay them off in the near future (for example, when receiving the billing statement), the allocation of purchases might be a dynamic decision. We acknowledge this, but argue an important point. Regardless of consumers' expectations, interest is charged immediately on purchases if consumers did not pay the previous balances in full. Therefore, dynamic considerations are only relevant when consumers start borrowing on any card. In the analysis below, we take these contractual features into account. First, we only use those months in which the cardholders paid at least the minimum due (about $75 \%$ of consumer-months in our sample). Second, we just consider observations in which consumers had outstanding balances in the two cards. This leaves us with 45,435 observations.

The distribution of the share of purchases allocated to the expensive card is reported in the upper left panel of Figure 5. As before, the unit of analysis is a consumer-month. For every period, the share of purchases is defined as the sum of purchases made with a given card, divided by the total purchases undertaken with the two cards. The distribution is bimodal with about $25 \%$ selecting only the cheaper card, $25 \%$ making all of their purchases with the more expensive one, and the rest 
mixing up their two cards. These results indicate that consumers do not seem to follow interest rates when choosing which card to use. A troubling objection to this conclusion is the possibility that consumers choose to use an expensive card whenever spending on their cheaper card might surpass the credit limit. Thus, the observed allocations could be affected by this behavior. To get an idea about how relevant this constraint is, the upper right panel of Figure 5 displays the distribution that would have arisen had consumers purchase up to the credit limit with the cheaper card, and the rest with the more expensive one. The figure shows the importance of this constraint. The credit limit binds for $43 \%$ of the observations, while for the remaining $57 \%$, it is feasible to allocate all purchases on the cheaper card. Yet, the actual number of individuals following this allocation is significantly smaller.

To further examine whether the limit constraint is driving the results, we redraw the previous figure using only observations for which consumers' total purchases could fit in both of their credit cards (18,055 observations). The results are displayed in the lower left panel of Figure 5. The distribution is extremely similar to that previously reported. Finally, to check whether small differences in the interest rate could be driving our findings, we use the last sample to estimate the distribution of the fraction of purchases allocated to the expensive card by terciles of interest rate differentials. The results are displayed in the lower right panel of Figure 5. There are no significant changes in the documented behavior. While not shown, we find that in linear regressions, decile indicators of the interest rate differential explain only $0.03 \%$ of the variance in the share of purchases. These results hold when we restrict the sample to observations in which total purchases surpasses $\$ 1,000$ pesos. Overall, these findings indicate that, despite the high heterogeneity of consumers, on average interest rate differentials do not determine the way consumers allocate their monthly purchases between the cards available in their wallets.

In summary, consumers do not seem to follow interest rate differentials but instead abide by other systematic rules. The actual factors determining allocations are an empirical question. This is the goal of our next section.

\section{$5 \quad$ Empirical Analysis}

Once we depart from allocations based on interest rate differentials, it is not easy to come up with an alternative model. In order to guide our search, we designed and applied a small survey in several public places of Mexico City during July, 2006. ${ }^{9}$ We interviewed people until we gathered 200 individuals who had at least two comparable credit cards, carried interest paying debt on at least one of them and whose average utilization rate in the month before the interview was below

\footnotetext{
${ }^{9}$ Due to budgetary and time constraints, the sample size is small and the range of questions is limited. Although a larger and more rigorous survey would be required to properly evaluate the usage of heuristics, our survey can still provide a guide to behavioral patterns to look for in the data.
} 
0.6. ${ }^{10}$ We asked for respondents with low utilization rates to avoid situations in which individuals make their decisions purely on the basis of credit limit constraints. We asked respondents about the identity of the credit cards in which they carried outstanding balances on and then, inquired about the interest rate on them. We asked respondents who carried debt on a more expensive card about the reasons to do so. We showed them several answers including an alternative for respondents to talk about not listed options. Note that we asked about the reasons to borrow on a certain card, not about the reasons to use it. Therefore, our answers combine motives such as preferences, usage patterns as well expectations at the time of spending.

Of the 200 consumers, $67 \%$ (134) claimed they knew for certain which card was more expensive (although many of them did not know the exact interest rates). Out of this, 29 respondents sustained the interest rate in all their credit cards was equal. From the 105 individuals remaining, $76 \%$ (80) holds interest paying debt on the more expensive card; their reasons were as follows: a) $3 \%$ (3) answered that they thought they would be able to pay the expensive card but in the end, they could not; b) 3\% (3) said they were concerned about one of their cards to be stolen or incorrectly rejected at a store, so having available limit in both cards was an insurance against these kinds of events; c) $43 \%$ (34) replied that they did not like to have "too much" debt on a single credit card, even though they had available revolving credit on the cheaper one; d) $8 \%$ (6) said that they preferred to have available credit limit on both cards; e) 31\% (25) answered they used different cards for different purposes and; f) $11 \%$ (9) said that they had not thought about it.

Answers a) and b) are some of the standard arguments found in the literature, however only $6 \%$ of respondents chose them. Interestingly, only $3 \%$ of the surveyed consumers selected option a), which features prominently in Ausubel (1991). This provides support to our assumption that dynamic considerations play a smaller role in the allocation problem. Options c) and d) are consistent with the idea that consumers aim to keep a constant utilization rate in their credit cards. This motive is consistent with the results obtained by Gross and Souleles (2002). We refer to it as the "debt equalization" heuristic. Finally, a considerable amount of consumers selected option e), which is closely tied to categorization of purchases and mental accounting [Thaler (1985), Thaler (1999), Prelec and Loewenstein (1998) and Ranyard et al. (2006)]. Taken together, these answers support the idea that consumers follow rules other than interest rates when deciding which credit card to borrow from. In what follows, we use these answers to guide our data analysis.

\subsection{Determinants of the allocation of payments}

We begin by studying the determinants of the allocation of payments between cards. In particular, we focus on the role of possible heuristics and study whether proxies for such behavioral

\footnotetext{
${ }^{10}$ To calculate the total utilization rate, we asked individuals about the sum of interest paying debt and credit limit on their cards.
} 
rules can explain the variation in the observed allocations better than interest rates do. As before, we condition on individuals holding outstanding balances on their two cards. We initially focus on cases in which consumers make the minimum payment on both cards. This sample includes 65,134 observations. We focus on this sample to exclude situations in which consumers are constrained by the minimum payments or miss the due dates. Later on, we incorporate these cases. For the analysis, we randomly select one of consumers' credit cards and labeled it as card 1. We keep this label invariant throughout the investigation.

Since we select observations in which both minimum payments are met, our goal here is to identify factors that could influence the fraction of payments above the minimum due allocated to a given card. We model this fraction for a given consumer and time period as a simple function of a set of time-varying indicators of interest rate differentials, debt differentials and recent credit card activity. Specifically, our estimation of interest is:

$$
S H P A Y 1_{i t}=\beta_{0}+\beta_{1} C H E A P 1_{i t}+\beta_{2} D H 1_{i t}+\beta_{3} X H 1_{i t-1}+\gamma X_{i t}+\epsilon_{i t}
$$

where $S H P A Y 1_{i t}$ denotes the fraction of payments above the minimum due that are allocated to card 1 by consumer $i$ at time $t, C H E A P 1_{i t}$ is a dummy variable equal to one if the interest rate on card 1 is lower than the rate on card 2, $D C 1_{i t}$ is an indicator coded one if the outstanding balances on card 1 at the beginning of period $t$ are greater than those on the other card, and $X H 1_{i t}$ is a dummy equal to one if the purchases on card 1 are greater than the spending on card 2 . The vector $X_{i t}$ contains interaction terms and controls such as quartile indicators for total payments above the minimum due, time invariant variables such as average payments per consumer, average debt per consumer and bank indicators. Finally, $\epsilon_{i t}$ is the error term.

A complication arises when two cards have the same interest rate, purchases or debt. In these cases, we selected randomly which card had a larger value. We followed this approach to avoid dropping observations with potentially useful information. Our results however, are robust to excluding these cases.

In this regression, an observation is a consumer-month. Since all covariates are dummy variables, this specification is a comparison of means. Our identification comes from time series and cross section variation. In the case of interest rate differentials, identification is principally due to cross section variation in whether different cards have different interest rates. Nonetheless, the fact that banks send temporary reductions in the interest rate (or teaser rate offers) to certain cardholders provides a little bit of time-series variation.

The coefficients on the term $C H E A P 1_{i t}$ capture the average difference in $S H P A Y E X P_{i t}$ when card 1 has a lower interest rate than card 2. If consumers take into account interest rates when allocating their monthly payments, this coefficient should be negative and significant. Meanwhile, 
the coefficient on $D H 1_{i t}$ measures the effect of the outstanding balances on card 1 on the fraction allocated to pay them off. We use this covariate to test the hypothesis that individuals tend to pay off cards which have more outstanding balances (debt equalization heuristic). Finally, the coefficient on $X H 1_{i t}$ measures the effect of previous spending on card 1 on the fraction allocated to repay this card. We include this covariate to indirectly capture the idea of categorization. If consumers use a credit card for borrowing and another one for spending, they should allocate an important amount to pay off the purchases made during the previous billing cycle. In addition, we include quartile indicators for total payments above the minimum to make sure our results are not driven by small stakes. Once we include these indicators, the coefficients on the explanatory variables are identified by variation within those quartiles. Similarly, we include time invariant variables to control as much as possible for possible cross-section omitted characteristics that could bias our estimates. Finally, bank dummies are added to the specification to take into account bank-specific characteristics such as promotions not captured by our initial matching or other customer-bank relationships. At first, we estimate regression 1 by OLS, with clustered standard errors within consumers. Next, we recognize the censoring in the dependent variable and use a Tobit model as our baseline specification.

Regression results are presented in Table 3. Each column shows a separate regression. Column (1) presents results for the OLS estimates of equation 1. All coefficients are statistically significant. The first thing to note is that the coefficient on the interest rate indicator is economically small and with a wrong sign. This confirms our results that cardholders do not go by interest rates when allocating their monthly payments. More interestingly, individuals allocate a larger fraction of their payments above the minimum due, to cards with larger balances and with higher spending. According to the estimates in column (1), if a card has more debt, then the fraction of payments over the minimum allocated to pay it off is 0.05 higher. If in addition, the preceding spending on the card is relatively larger, then the estimated fraction increases by 0.12 (almost half of a standard deviation).

Regression (2) examines whether there are interactions. When interaction terms are included, the main coefficients do not change. In most cases, the coefficients on the interaction terms are not significant at the $10 \%$ level. The Wald test that all interaction terms are jointly zero cannot be rejected at standard significance levels. Since there is no substantial statistical difference when these covariates are included, we stick to our basic specification. In Column (3), we use a Tobit regression to account for the fact that the dependent variable is censored at zero and one. Despite the double censoring, the estimates of the linear model correspond closely to the Tobit model results, suggesting that reliance on the linear model is reasonable. We use this model as our baseline, unless stated otherwise.

To check the robustness of our estimates, we considered a few variations on the reported re- 
gressions. Column (4) examines whether results depend on the gap between interest rates. We re-estimate our baseline model excluding observations for which the interest rate differential is smaller than the median (1.1\% per month). There are no significant changes in the estimated effects. Next, we investigate the possibility that the effects of non-price characteristics are the result of a time-invariant omitted variable and estimate equation 1 including individual fixed effects. Because it is not straightforward to incorporate fixed effects into a Tobit specification, we use a linear model. ${ }^{11}$ Here, coefficients are solely identified by time series variation. In the case of interest rates, this variation comes from temporary reductions in the interest rates (or teaser rate offers). We present the results in Column (5). Although the coefficient on $X H 1_{i t}$ is smaller, the results are generally similar. In fact, the regression $R^{2}$ drops when fixed effects are included, suggesting these effects account only for a small variation in the data.

Regression (6) is a modification of regression (3), in which continuous variables are used instead of indicator variables. The effects are qualitatively similar, indicating that results are not sensitive to what measures are actually used in the regression. In column (7) we reproduce the base regression using observations in which the debt differential between cards is larger than the median $(\$ 4,280$ pesos). If consumers look at debt differentials when allocating their payments, the effect should be larger when this difference is more evident. As expected, the estimates coincide, but the effect of debt is larger in magnitude.

A possible concern could be that, as a result of the teaser rate offers, consumers are not able to track the identity of the card with the lower interest rate. To investigate this possibility, regression (8) re-estimates the base model using consumers whose cards never changed ranks; that is, we include only individuals whose cheaper card had always a lower interest rate than their more expensive one. Little changes in this regression. Another possibility is that cardholders are restricted by the closing dates of their cards. For instance, consumers may pay less to the more expensive card because the due date on this card is before payday, while the deadline on the other one is after that. This argument could explain why interest rates play no role in the allocation of payments, although it would have difficulties in justifying why the other covariates are different from zero. We run the basic model using consumers whose credit cards have a closing date differential of eight days or less. The estimated parameters are shown in column (9). The coefficients on the regression remain unchanged.

In spite of using controls for the total amount paid above the minimum, a possible objection to our results is that consumers may pay off small amounts for their decision to matter. To assess this, we re-estimate our model restricting the sample to observations in the highest quartile of total payments above the minimum. This regression is particularly interesting for studying the role

\footnotetext{
${ }^{11}$ This is because the maximum likelihood estimator in nonlinear panel data models with fixed effects is biased and inconsistent.
} 
of debt and purchases on allocation decisions. This is because consumers tend to evaluate more carefully decisions involving significant amounts of money. More specifically, there are two scenarios in which consumers could make large payments. The first one involves individuals who constantly borrow heavily and have the liquidity to promptly pay off their debt. The effect of this individuals is captured by the time invariant regressors. The second situation relates to cardholders who hold debt and occasionally receive extra liquidity to pay it off (for example salary bonus, Christmas bonus or tax refunds). If features other than interest rates are important, it is likely they will show up in these cases. Column (10) displays the estimated coefficients. The general pattern of the estimates is similar to the previous regressions, but the effects are substantially larger in magnitude, supporting the view that debt and previous purchases are quite important for consumers when deciding how to allocate larger credit card payments. The regression $R^{2}$ jumps considerably in this regression. Interestingly, the interest rate indicator is negative and larger in size, suggesting consumers pay more attention to interest rates when the amount paid is large.

Thus far we have concentrated on cases in which consumers make at least the minimum payment due on both cards. This was to simplify the analysis and interpretation. We now consider those situations in which cardholders make at least the minimum payment on just one card. These situations present further challenges, however. On one hand, since the observations in this sample miss at least one minimum payment, the analysis of payments above the minimum is meaningless. On the other hand, analyzing the allocation of total payments can be misleading due to the minimum payment constraints. As an alternative, we study which card consumers choose to make the minimum payment on (given that only one minimum payment was actually made). We extend the preceding analysis and study the effect of interest rates, debt differentials and previous purchases on the probability of making the minimum payment due. The basic idea is simple. If individuals missed the minimum payment despite it was feasible for them to meet both of their minimum payment obligations (cases $\mathrm{B}$ and $\mathrm{C}$ in Figure 6), it must be because they lost the billing statement (or some other unlucky situation), missed the due date (or forgot about it), or preferred to allocate the funds to repay some other card. The first case is simply randomness. The second and third cases however, imply that individuals pay more attention to cards with certain characteristics or alternatively, prefer to repay some of them first. In either case, the features of those cards contain information about which factors matter for consumers when allocating their monthly payments.

Table 4 reports the marginal effects of the probit regressions using the same covariates described in the preceding analysis, excluding the quartile dummies. Our sample consists of consumers who missed the minimum payment on one card, despite it was feasible for them to cover it up during that period (as the total amount paid to both cards is larger than the sum of the minimum payments). Our dependent variable is an indicator that equals one if the individual made the minimum payment to card 1 in that month. The unit of analysis is a consumer-month. Column (1) displays the base 
model. The estimates are quite consistent with our previous results. As before, interest rates play no role in the decision to make the minimum payment. More interestingly, consumers tend to make the minimum payment on cards with more debt and higher purchases. Cards with more debt and higher purchases are $19 \%$ and $31 \%$ more likely to be repaid, respectively. The results when we restrict the sample to observations with a large interest rate gap or closer due dates are similar and confirm our findings.

In summary, the estimates for all specifications in this section support the claim that debt and previous purchases are more influential than interest rates in explaining how consumers allocate their monthly payments. These findings are consistent with the view that individuals rely on heuristics or alternatively, lack the sophistication when making financial decisions. The estimates also point in the direction of there being specialization in the use of cards. This is supported by the fact that spending affects significantly the allocation of payments. Moreover, the fact that this result comes through in the fixed effect regression suggests inertia in the use of credit cards. We explore these issues further in the next section.

\subsection{Determinants of the allocation of purchases}

In the previous section, we showed a positive relationship between previous purchases and current monthly payments and interpret this as suggestive evidence of specialization and inertia. In this section, we provide further evidence to support these conclusions.

We study the determinants of the purchase allocation decisions. We estimate a series of regressions to measure the relative importance of the factors that could impact consumers' choices. This analysis is a bit complicated due to the constraints imposed by the credit limits. We tackle this problem by segmenting the sample and incorporating the proper restrictions into each subsample. To get an idea of how these constraints work, we use a convenient graph tool. Figure 7 shows in a two-dimensional diagram all possible allocations $\left(X_{1}, X_{2}\right)$. The basic idea here is that consumers pick a purchase allocation $\left(X_{1}, X_{2}\right)$ out of those that add up to the total amount spent in a given month $X_{1 \text { Observed }}+X_{2 \text { Observed }}{ }^{12}$ Consumers cannot choose freely, though. Given their total spending, consumers are restricted by the available limit on their credit cards. Fortunately, these constraints can easily be incorporated into the graph. The dotted lines represent the available credit limit (credit limit minus outstanding balances) in card 1 and card 2. Here, we assume that the available limit in card 1 is larger than the available limit in card 2 . The red line is the "card 1 constraint", namely those bundles that fit into card 1. Similarly, the blue line is the "card 2 constraint". The triangle A comprises allocations that fit into both cards. Meanwhile, areas B and C measure combinations that could fit into card 1 but cannot fit into card 2 (or the card with less available limit). Region D represents bundles that cannot fit entirely on any card. Each region

\footnotetext{
${ }^{12}$ These "feasible" bundles are given by the line $X_{1}+X_{2}=X_{1 \text { Observed }}+X_{2 \text { Observed }}$
} 
presents different challenges. For instance, allocations in areas $\mathrm{B}$ and $\mathrm{C}$ are likely to be influenced by the fact that both purchases could fit on the card with more available limit but not on the other one. In order to properly identify which factors affect allocations, we must take this into account.

We begin by analyzing observations in area A. This is the simplest scenario as none of the limit constraints bind; that is all purchases could fit in either card. Next, we select observations in areas $\mathrm{B}$ and $\mathrm{C}$ and incorporate the fact that total spending could fit only on one card. Finally, we analyze allocations that cannot fit on any card (Region D). Throughout the analysis, we restrict the sample to include only observations in which consumers made at least the minimum due on both cards (to avoid cases in which one card was put "on hold") and had outstanding balances in their two cards. In addition, we eliminate observations in which consumers surpass the credit limit on both cards. This reduces the sample to 32,267 observations.

We focus on the fraction of purchases allocated to a randomly selected card. We model this fraction as a function of indicator variables of interest rate differentials, previous spending, differences in debt, differences in available limits, and tenure gaps. More specifically, we estimate the following specification:

$$
S H X 1_{i t}=\beta_{0}+\beta_{1} C H E A P 1_{i t}+\beta_{2}+X H 1_{i t 1}+\beta_{3} D H 1_{i t}+\beta_{4} A V L 1_{i t}+\beta_{5} T E N 1_{i t}+\gamma X_{i t}+\eta_{i t}
$$

The dependent variable $S H \quad X 1_{i t}$ denotes the fraction of purchases allocated to card 1 by consumer $i$ at time $t$. The covariates $C H E A P 1_{i t}, D H 1_{i t}$ and $X 1_{i t-1}$ are defined as in the previous section. The term $A V L 1_{i t}$ is an indicator coded one if card 1 has more available limit (limit minus outstanding balances) than card 2 , and $T E N 1_{i t}$ is a dummy equal to one if the age of card 1 , computed as the time in months since booking, is older than the age of card 2. The vector $X_{i t}$ contains controls such as polynomials of total purchases, total debt and total available limit, time invariant variables such as average purchases per consumer, average debt per consumer, average available limit per consumer and bank indicators, as well as quartile indicators for debt differentials and available limit differentials.

As before, an observation is a consumer-month. The identification strategy is based on comparisons across time and across individuals. We include time invariant variables to control as much as possible for cross-section characteristics that could affect our estimates. These covariates attempt to control for the cross-section heterogeneity in credit card use and borrowing. Additionally, since we include quartile indicators for debt and available limit differentials, our identification comes from comparisons within these groups.

The intuition behind $C H E A P 1_{i t}$ is the same as in equation 1 . The coefficient on $X H 1_{i t}$ measures the effect of previous spending on card 1 on the current purchases allocated to it. This covariate directly captures the idea of inertia (inclination to repeat-purchase a brand over succes- 
sive purchases) or brand loyalty that we sketched in the previous section. If inertia exists, this coefficient should be positive. The coefficient on $D H 1_{i t}$ measures how outstanding balances impact the allocation of purchases. One might expect this coefficient to be negative if consumers tend to equalize debt across cards (debt equalization heuristic). This correlation however, could be positive if $D H 1_{i t}$ proxies for unobserved brand preferences. More precisely, consumers may purchase with the card carrying more debt simply because this is the card they frequently use but not pay in full. We indirectly control for this effect by including $X H 1_{i t}$ as a covariate in the regressions. However, to the extent that purchases were made before the anterior period, this effect could still remain. The coefficient on $A V L 1_{i t}$ measures how credit limit constraints affect the allocation of purchases. If constraints are important, this coefficient should be positive. Finally, the coefficient on $T E N 1_{i t}$ measures the effect of age. The theoretical prediction on how this covariate should relate to the allocation of purchases is not clear, though.

Table 5 contains the results for an array of several specifications -each row is a separate regression. The point to presenting these alternatives is to show the robustness of the results. In columns (1) - (3), the sample includes observations for which all purchases could fit in either of consumers' credit cards without surpassing the credit limits (area A in Figure 7). The results in columns (4) - (6) are derived from the sample in areas B and C, that is, allocations that could fit into the card with the largest available limit but not into the other one. This is a sample of 8,380 consumer-months observations. Column (7) presents results for the sample of allocations that cannot fit entirely on any card (Region D). Since double censoring is prevalent, we use a Tobit specification in all cases.

Column (1) reports the base regression. Almost all coefficients are statistically significant at conventional levels. The only exception is the coefficient on the debt differential indicator. This fact may simply reflect that the two effects previously mentioned offset each other. While most coefficients are significant, it is noteworthy that these characteristics explain only a small part of the variation in the allocation of purchases. The most important determinant of the fraction of purchases allocated to a given card is whether a larger fraction of purchases were allocated to that card in the previous period. The magnitude and significance of the coefficient indicates that consumers are very likely to repeat purchases with the same credit card. This is consistent with the idea of inertia in favor of repeat purchase. On the other hand, the share of purchases allocated to a given card augments by 0.09 if this card is cheaper. Limit constraints are statistically although not economically significant. Since the sample includes only observations for which limit constraints do not bind, this could be interpreted as evidence against the hypothesis that consumers equalize utilization rates (debt/limit). Interestingly, the fraction of purchases allocated to a random card is estimated to increase by 0.09 when this card is older. These facts have interesting market equilibrium implications, which we explore in more detail in section 7. 
Column (2) presents the estimates when we restrict the sample and include only observations for which the interest rate gap is above the median (1.1\%). Results do not change substantially. The indicator of previous purchases allocation continues to be the most important determinant of the contemporaneous allocation. Regression (3) focuses on large purchases. Again, the assumption behind this regression is that individuals tend to pay more attention to decisions involving significant amounts of money. We rerun our base specification using a reduced sample of observations in the highest quartile of the total purchases distribution. Overall, the estimated coefficients do not change substantially, although the point estimate of the indicator for previous purchases drops when restricting the sample this way. Although not reported in the table, the estimated coefficient on the bank dummies significantly increased. The change in the bank indicator coefficients and the reduction in magnitude of the lagged spending covariate indicate that individuals stick less to their frequently used card when making large purchases and instead, seem to pick a card based on idiosyncratic characteristics, such as awards schemes not captured by our initial matching, promotions on departmental stores or other customer-bank relationships. ${ }^{13}$

We now turn to cases for which the limit constraints bind. Column (4) reports the base regression with a sample of observations for which total spending exceeds the available limit on one card, but is smaller than the available limit on the other one. In general, results are in the same line as those previously reported. Still, there are some interesting differences. Although the indicator of purchases remains economically and statistically significant, it is not the main determinant of allocation here. Consistent with the presence of credit limit constraints, individuals allocate a larger fraction of their purchases to the card with more available limit. Specifically, the fraction of purchases allocated to a random card is 0.39 larger when this card has a larger available limit. This pattern holds true in regressions restricting the sample to cases with large interest rate gaps (column (5)) or observations in the highest quartile of the total purchases distribution (column (6)). Finally, column (7) displays the results when we use observations for which total purchases cannot fit entirely on any card. The allocation of purchases continues to be driven by inertia and credit limit constraints. For instance, the fraction of purchases allocated to a given card increases by 0.26 and 0.25 when it is charged with more purchases in the previous period and when it has more available limit, respectively.

In summary, our analysis of this section documents three main findings. First, consumers do not go by interest rates when deciding which card to purchase with. Second, although there is substantial heterogeneity in the reasons to pick a credit card to purchase with in the first place, consumers adhere to their choices and repeat purchases with the same card. This supports the

\footnotetext{
${ }^{13}$ The marketing literature has studied the influence of psychological and economic treatments on consumer choices. In the economics literature, Bertrand, Karlin, Mullainathan, Shafir and Zinman (2005) show that consumers' choices are influenced by non-pecuniary features. In Mexico, the proliferation of cards with different logos and shapes could be an indicator of this tendency.
} 
idea of inertia in the marketing literature and the so-called "front of the wallet" behavior in the

credit card jargon. Inertial tendencies are not fully explained by small and recurrent purchases and automatic deductions, as they are also present when we focus on large purchases. Finally, consumers tend to switch more when purchases are large. In these cases, they seem to pay a bit more attention to interest rates and idiosyncratic credit card features.

\section{Possible explanations}

The analysis in our study so far suggests that consumers look at credit card characteristics other than interest rates when deciding how to allocate their debt. The main findings are:

- Consumers do not go by interest rates when deciding which card to pay off or to purchase with.

- Individuals tend to use the same card and pay it off immediately afterward.

- In addition to this behavior, cardholders look at other features when making large purchases or large payments. In the first case, individuals tend to allocate larger payments to cards with more debt. In the later case, consumers pay more attention to idiosyncratic credit card features.

These findings seem to support the idea that individuals systematically use one credit card for recurrent purchases and another one for larger expenditures, regardless of the interest rates. The results also suggest that non-pecuniary features play an important role for consumers when making important financial decisions. Assuming (1) homogeneous goods, (2) no switching costs, and (3) perfect information, these results are difficult to reconcile with a cost minimizing model. Still, there are two possible objections to this conclusion. The first one is that the previous assumptions may not be true in our setting. Although the first and second assumptions seem quite plausible considering the way we constructed the sample, the last assumption is more questionable. Namely, consumers may ignore the interest rate of their cards. In the first subsection, we investigate how likely this supposition is. The second objection is that consumers do not care about interest rate differentials due to the low stakes involved and therefore, find easier to stick to some other rules. In the second subsection, we address this concern and calculate the monetary cost of mistakes. Finally, in the third subsection, we argue that our results are more consistent with hypotheses related to mental accounting and financial unsophistication.

\subsection{Do consumers know the interest rates of their credit cards?}

Consumers may exhibit the previous behavior because they do not know the interest rate of their credit cards. Testing for this hypothesis however, is complicated. An ideal test is to survey 
cardholders in our sample and ask them about the interest rate of their credit cards. This procedure however, is expensive and unfeasible due to confidentiality constraints. As a proxy, we elicit the proportion of consumers who know the interest rates of their cards using a survey of 200 randomly chosen respondents interviewed in public places in Mexico City with at least two credit cards. Among the questions of the survey, we asked individuals about the interest rates of their credit cards as well as their relative rank (in terms of interest rates) during the preceding month. The proportion of respondents who identified the exact rates (or a close rounded number) was 53\%, while the percentage who knew how cards were ranked reached $67 \%$. These figures give us a rough sense of consumers' acquaintance with interest rates. Nonetheless, as we cannot observe the actual allocations of respondents, these numbers should be interpreted as a purely descriptive exercise.

An alternative test is to analyze the behavior of consumers who recently received a reminder letter from banks concerning the interest rate of their credit cards. The basic idea here is that consumers are more likely to recognize interest rates after receiving this notice. Unfortunately for us, banks hardly ever send these announcements without other promotions. What banks do send, however, are temporary reductions in the interest rate or teaser rate offers (TROs). These offers are widespread in Mexico. In 2005, the average credit card had an active TRO for approximately 2.1 months. TROs usually represent an important reduction in the interest rates. In our sample, the average interest rate during the teaser period was $1.3 \%$. Banks send these offers by mail to selected customers. These letters include the description of the TROs as well as the otherwise applicable interest rates. We use these offers as proxies for interest rate reminders.

Our exercise has two steps. In the first one, we identify cardholders who received at least one TRO, and analyze how they reacted to it. This is to assess whether consumers are aware of the changes in the interest rates and consequently, of the rates that regularly apply. Although not the main focus of this exercise, we also asses whether consumers substitute debt between cards. Next, we reproduce our previous analysis but restrict our sample to observations after the teaser period. This approach is the best available, given our data. Still, two possible concerns remain. First, limiting the analysis to individuals who received a teaser rate offer can introduce selection bias if the selection rule of the bank is correlated with allocations. For instance, banks could target TROs to consumers borrowing on other cards or who are not using the cards issued by them. Fortunately, this is not very likely here, as banks in Mexico cannot observe activity in other credit cards. Indeed, we find no statistical difference in the average allocation of payments and purchases between the full sample and the reduced sample, suggesting that the selection is unbiased for our purposes. A second concern is that even if consumers realize one of the interest rates after receiving a TRO, this does not imply they will be aware of the other one. To address this, we re-estimate our specification using data for consumers who got teaser rate offers on both cards, after they received the last one.

We begin by investigating whether consumers react to temporary changes in the interest rate. 
Our empirical strategy regresses changes in debt, purchases or payments in a given card, on indicators of teaser rate offers, their forwards and lags, as well as a full set of controls. The base specification mirrors that used in previous research, e.g. Gross and Souleles (2002), except that these authors utilize changes in the interest rates as regressors. In contrast, we employ indicator variables of the TROs as covariates. This is to acknowledge that TROs are temporary. In Mexico, most of these offers last one or three months ( $82 \%$ in our sample). We concentrate on these two types. To properly account for these differences in duration, we introduce separate covariates for each kind of TRO. The unit of analysis is a consumer-month. The estimating equation of primary interest is:

$$
\begin{aligned}
\Delta Y_{i t}=\alpha+\sum_{j=1}^{n} \beta_{j} T R 1 M 1_{i t+j}+\gamma_{1} T R 1 M 1_{i t}+\sum_{k=1}^{n} \delta_{k} T R 1 M 1_{i t-k}+\sum_{l=1}^{n} \rho_{l} T R 3 M 1_{i t+l} \\
\quad+\theta_{1} T R 3 M 1_{i t}+\theta_{2} T R 3 M 2_{i t}+\theta_{3} T R 3 M 3_{i t}+\sum_{m=1}^{n} \phi_{m} T R 3 M 3_{i t-m}+\lambda^{\prime} X+\epsilon_{i t}
\end{aligned}
$$

where $\Delta Y_{i t}$ is either the change in actual debt, purchases or payments in card 1 or the change in debt on card 2. The term $T R 1 M 1_{i t}$ is an indicator equal to one if individual $i$ received a one month TRO on card 1 during period $t$. The covariates $T R 3 M 1_{i t}$, TR3M2 $2_{i t}$ and $T R 3 M 3_{i t}$ are indicator variables coded one for the first, second, or third month of the three month TRO received on card 1 , by individual $i$ at time $t$. The covariates in $X$ are additional controls that include binary variables for other changes in interest rates, indicators for changes in credit limit and its lags, time dummies, and covariates to account for the selection rule of the banks. These regressors include previous utilization rates and previous delinquencies. We include this covariates to control for an omitted variable bias that could arise due to the nonrandom credit supply decision of banks. ${ }^{14}$ In addition, we include individual fixed effects. ${ }^{15}$ Finally, since our panel is unbalanced and there is only one year of information available for one bank, we include two forwards and three lags for each one of the offers.

We estimate equation 3 by OLS, with clustered standard errors within accounts. Table 6 presents the results. Each column corresponds to a different dependent variable. Column (1) reports the estimates using the change in debt in card 1 as the outcome of interest. Consumers respond substantially and immediately to the two kinds of offers. In the case of the 1-month TROs, the average debt increases by $\$ 352$ pesos at the time of the announcement plus $\$ 1,935$ pesos during

\footnotetext{
${ }^{14}$ For example, if banks extend teaser rate offers to consumers who are not using their card and who have a low elasticity with respect to temporary changes in the interest rate, then our estimates for the population will be biased downwards (although it would be correct for the treated population). Conversely, if banks target consumers who are increasing their debt, it is possible that we incorrectly attribute differences in debt (or the dependent variable) to TROs.

${ }^{15}$ With fixed effects, the coefficients of interest are identified by departures from the average change in debt.
} 
the first month of the offer. The corresponding figures for the 3 -month TROs are $\$ 1,020$ and $\$ 2,064$. In addition, average debt either decreases or remains invariant during the month following the teaser period. Columns (2) and (3) present the estimates using the change in purchases and payments in card 1 as dependent variables, respectively. The regressions confirm the prior patterns. Purchases are estimated to increase at the beginning of the teaser period and decrease afterward. Conversely, payments decrease at the beginning but increase significantly when the TRO expires. These results confirm our supposition that consumers are aware of changes in the interest rates and suggest individuals must be familiarized with the rates typically charged.

Column (4) reports an additional regression using the change in debt in card 2 as dependent variable. Although not directly related to the goal of this section, we run this regression to investigate the sensitivity of debt in one card to changes in the interest rate of the other one. These findings are of potential interest. The estimate for the effect of teaser rate offers on debt in other cards is insignificantly different from zero. This support our previous findings and provides evidence against there being substitution of debt between credit cards. In fact, these estimates suggest that consumers pay attention to time-varying changes but not to time-invariant differences in interest rates. Overall, these results reinforce the interpretation that consumers categorize their expenditures in mental accounts or simply lack the financial sophistication to manage their personal finances.

We show above that consumers receiving TROs are actually aware of the applicable interest rates. We now investigate how these consumers allocate their monthly payments and purchases. We re-estimate equations 1 and 2 restricting the sample to periods following the expiration of the first teaser offer (in case consumers received any). Column (11) in Table 3 displays the results. In general, there does not appear to be an important difference with the base estimation, although individuals are estimated to assign a larger share of their payments above the minimum to the more expensive card and to the card with more outstanding balances. These figures are likely attributable to the payments made to the card receiving the TRO. Using the information on TROs, it is possible to construct a smaller sample of consumers that received at least one TRO on both of their cards. If consumers are aware of the interest rates after receiving a TRO, consumers in this sample should be presumably familiar with the terms of their two cards. The analysis for those observations is displayed in the last column of Table 3. Results do not change if we restrict the sample this way. The estimations for the purchases specification using both samples are presented in columns (8) and (9) of Table 5. Limiting the sample to observations following a teaser period slightly reduces the magnitude of the effect of previous purchases, but in general, results are consistent with the estimates obtained previously. In an unreported regression, we re-estimate these equations excluding observations for which the interest rate differential is smaller than the median. There are no significant changes in the estimated effects. Overall, these results seem to reject the hypothesis 
that individuals abide by interest rates after introducing reminders about them. While TRO may not be the best proxy for interest rate reminders, our findings cast doubts on the hypothesis that results in section 5 are mainly driven by unawareness about interest rates.

\subsection{Small stakes}

Sections 4 and 5 show that consumers do not allocate their monthly purchases and payments based on the interest rate differential between their credit cards. Yet, this is not inconsistent with a neoclassical choice model, unless these deviations are systematic, costly and prevalent In this case, a choice model based on heuristics might be more appropriate. We already showed that deviations are systematic. In this section, we focus on the last two of these features and calculate the monetary costs of mistakes. We set up a static model of optimal intra-temporal allocation of credit card payments and purchases, conditional on the purchases undertaken with both cards and the total amount repaid to them. ${ }^{16}$ We use this model as a benchmark against which the actual financing costs can be compared. The main advantage of such a model is that it allows us to formally introduce into the decision problem contractual features such as the minimum payment due, the credit limit and fees.

The model is a simple period-by-period cost minimization problem. A formal description is presented in the Appendix. We solve the model and derive the optimal purchases and payments for each card, period and consumer. Next, we use these allocations to estimate the optimal financing costs for each individual. With this at hand, we compare these costs with the actual financing costs faced by each cardholder and calculate the monetary costs of mistakes. We refer to these extra expenditures as misallocation costs.

We measure financing costs as the sum of interest costs and fees. Although our main interest is in interest cost, we incorporate the cost of fees in our analysis. This is because fees could also be a consequence of allocation mistakes. For example, overlimit fees could be avoided by assigning part of the spending to another card. However, since the financing cost is additive, we are able to disaggregate the misallocation cost into extra interest and extra fees. ${ }^{17}$ Table 2 presents the percentage of observations in which individuals incur in misallocation costs, disaggregated by its source. The table shows that mistakes are very frequent. In $84 \%$ of the cases, consumers pay extra costs due to the wrong allocation of payments or purchases. Most of these mistakes involve extra interest costs rather than additional fees, suggesting interest mistakes are likely to be persistent. To explore this hypothesis, Figure 8 presents the distribution of consumers by the frequency they pay

\footnotetext{
${ }^{16}$ As already mentioned, conceptually our approach is equivalent to separating the consumer problem into two stages. In the first stage, individuals decide on the total credit card spending as well as the total amount to be repaid at the end of the month. In the second stage, consumers allocate these purchases and payments between their cards to minimize the interest costs and fees.

${ }^{17}$ We define extra interest (fees) as the actual interest (fees) cost minus the optimal interest (fees) cost.
} 
extra interest and extra fees. Here, the unit of analysis is a cardholder. Consumers seem to incur in extra fees rarely. About $27 \%$ never pays extra fees and about $65 \%$ do not incur in these fees at least $30 \%$ of the time. On the contrary, interest mistakes seem to be quite persistent. About $54 \%$ pays extra interest at least $70 \%$ of the time and $75 \%$ incurs in these mistakes at least $50 \%$ of the time. This persistence suggests consumers have an objective different from minimizing financing costs.

The previous table is silent about the magnitude of these mistakes. To address this, Figure 9 displays the distribution of the average misallocation cost. This cost is calculated for each consumer by taking the average of the monthly misallocation costs along time. The unit of analysis here is a cardholder. We focus on individuals rather than consumer-months to get a realistic measure of the cost faced by each person. To be more precise, using averages allows us to put a higher weight on costly but infrequent mistakes, such as those associated with large purchases, large payments and fees. The distribution in Figure 9 is skewed to the left. On average, consumers leave $\$ 82$ pesos on the table every month. Out of this, $\$ 45$ pesos correspond to extra interest cost. These results are not driven by outliers. The median of the distribution is $\$ 57$ pesos, which amounts to $0.006 \%$ of the median monthly income. These costs could be due however, to differences in the amount borrowed by distinct consumers. To examine the relative importance of these mistakes, we standardize the misallocation costs by dividing them by the average financing expenditure of each individual (interest accrued plus fees). The distribution of this measure is displayed in Figure 10. As before, the histogram is skewed to the left. The average individual leaves on the table a sum which amounts to $16 \%$ of her financing cost. The median individual leaves a sum which amounts to $10 \%$. For the 90 th percentile, more than $30 \%$ of the financing costs is due to misallocation mistakes.

A troubling objection to the previous results is the possibility that misallocation costs are highly influenced by overlimit and late payment fees. To further assess the relative importance of interest against fees, we combine Table 2 and Figure 9 and calculate the misallocation cost by source and deciles. Figure 11 shows the average misallocation cost within each decile, decomposed in extra interest costs and extra fees. Such desegregation allows us to assess the relative importance of both sources across the entire distribution of misallocation costs. With the exception of the top decile, interest and fees costs are spread fairly equally across the distribution. For the top decile, interest costs are significantly higher and add up to $\$ 2,228$ pesos. These results suggest that interest costs do constitute an important fraction of the money consumers leave on the table.

The cost of mistakes is not trivial, particularly when we compare it with other figures in the literature. Zinman (2007) uses the Survey of Consumer Finances for the United States to study foregone arbitrage between credit card debt and demand deposit accounts. He finds that "fewer than $10 \%$ of credit card holders could save as much as $\$ 10$ per month by managing their liquidity 
more aggressively". We look at missed arbitrage between much closer substitutes and with more accurate data. In spite of the presumably higher substitutability, we find larger sums left on the table. What is more, since mistakes are persistent, costs accumulate over time. These conclusions however, should be interpreted with caution as they may be influenced by factors such as interest rate differentials, fees and outstanding balances.

In summary, mistakes are very frequent. The cost of these mistakes is not trivial, but it is not so large either, and it is spread almost equally between extra interest and extra fees. What is more interesting is the fact that mistakes involving extra interests are quite persistent over time, suggesting consumers do not pay attention to interest rate differentials. Still, it is possible to argue that potential savings are not large enough to overcome the costs involved in performing the required calculations. We cannot prove this statement wrong. However, this explanation cannot fully rationalize the patterns documented in section 5. More specifically, if consumers do not really mind about which card to purchase with or to pay off, we should observe individuals choosing randomly between their two credit cards. Although there is substantial heterogeneity in consumers' choices, this implication contradicts our findings in section 5. Moreover, the fact that consumers respond to temporary changes in the interest rates suggest they actually care about small potential savings.

\subsection{Heuristics and financial unsophistication}

A final explanation for our results is related to behavioral theories and financial unsophistication. Behavioral explanations embrace mental accounting and the relevance of non-pecuniary features of the choice set.

Mental accounting refers to the cognitive operations used by individuals to organize, evaluate and keep track of their financial activities [Thaler (1985), Thaler (1999)]. An important component of these mental processes involve the assignment of expenditures to specific accounts. In our framework, these accounts are represented by credit cards. Mental accounting constitutes a compelling explanation for why individuals systematically use one card for recurrent purchases (as shown by the inertia in credit card spending), which is paid immediately afterward (as shown by the allocation of payments above the minimum), and another one for larger expenditures (as shown by the allocation of large purchases and large payments). Mental accounting can also rationalize why individuals tend to pay off cards with more outstanding balances, particularly when payments are large. More precisely, if budgets are not fungible, individuals may prefer to pay off cards that have been spent up to its limits and 'mentally' reduce the stress that a single large debt put on them. Therefore, a model of mental accounting can explain most of the findings in the paper.

An alternative explanation is that individuals do not understand how credit cards work or how interests are accrued. This is plausible because credit card features are complex. For example, 
individuals may pay the credit card with more debt, with the 'wrong' idea that it is more expensive because it accrues more interest. Unfortunately, there is no way to disentangle this hypothesis in the data. In any case, if financially unsophisticated consumers behave randomly, this explanation cannot fully rationalize the results in section 5, as consumers do not make random mistakes. A more reasonable story is that financially unsophisticated consumers stick to other rules. In fact, it is quite plausible for unsophisticated consumers to rely on mental accounts if these processes serve as substitutes for otherwise complex financial decisions. In this regard, financial unsophistication and mental accounting are not mutually exclusive.

In summary, out of the explanations above, the most successful ones, in our view, involve mental accounting and financial unsophistication. Nonetheless, we acknowledge that small costs, unawareness of interest rates and even the neoclassical model of allocation are also plausible explanations for some consumers or time periods, particularly when we take into account the enormous heterogeneity in the data.

\section{$7 \quad$ Supply side implications}

In this section we briefly discuss the supply side implications of our results. If consumers do not pay attention or do not understand interest rates, high and disperse prices can prevail in this market. This result mirrors the well understood effects of search and switching costs in the literature. Here, these costs include the cognitive efforts of performing mental calculations, the learning costs associated with these or alternatively, the mental costs of using a different card. Regardless of the motives, the implication is that banks will compete hard to attract 'new' customers in the first period, anticipating that if these clients borrow later on, they will do it on any card with available limit, regardless of the interest rate. In other words, since consumers can hold multiple credit cards, banks have incentives to assure clients keep the cards they issue in their wallets. This is particularly true when the market exhibits high inertia, as we documented before.

This up-front competition can take many forms, depending on the situation of the industry and the strategy used by each issuer. For instance, some banks could exploit the fact that consumers react to changes in the interest rates and compete on prices through introductory teaser rate offers. Likewise, other issuers could compete on the product space and introduce credit cards with rewards, mileages or logos. There is, in fact, substantial evidence that such strategies exist in the market. ${ }^{18}$

A natural question arises concerning why, if consumers do not pay attention to price differentials, some banks still compete up-front with low interest rate products (as we observe in our data). There are at least two reasons for this. First, certain consumers may indeed pay attention to prices and

\footnotetext{
${ }^{18}$ In Mexico, although introductory TROs are recent (mainly due to informational barriers), there is considerable evidence about such strategies on the product space.
} 
hold only low interest rate cards or alternatively, hold low and high interest rate cards but borrow mostly on the cheaper one. Second, as previously documented, many consumers take into account interest rates when making large purchases. In the end, whether a bank provides a certain kind of product depends on their assessment of the market demand for it.

Finally, our findings have another interesting implication. Namely, the fact that consumers allocate a larger fraction of their monthly purchases to their oldest card serves as an effective barrier to potential entrants. The extent to which these are relevant in practice requires further research.

\section{Conclusions}

Most consumers have more than one credit card. Yet, it is not evident how consumers manage these accounts. Here, we drew attention to the intra-temporal allocation of debt, payments and purchases among the credit cards consumers already hold. We constructed a novel data set that includes information on all the credit cards held by more than 10,000 consumers in Mexico. We find that the difference in the interest rates between homogeneous cards is not an important determinant of allocations. Namely, individuals do not borrow on their cheapest card despite it is feasible for them to do so. On average, these cardholders forego potential savings for a sum that amounts to $16 \%$ of their financing cost. We also present evidence on the main determinants of allocations. Consumers tend to put a larger fraction of their monthly payments and purchases on the card they spent more on during the preceding period. This fraction however, is smaller when consumers make either large payments or large purchases. In these cases, factors such as the identity of the card with more debt or idiosyncratic features of each plastic are also important. In other words, cardholders stick to the same card for recurrent purchases, but not necessarily for more important financial decisions; here non-pecuniary features and fungible limits play also a role. These results are difficult to reconcile with a standard cost minimizing model. We discuss potential explanations for these findings. Although we cannot fully disregard some hypotheses, we believe the most compelling explanation is mental accounting and financial unsophistication. Nonetheless, further research is necessary to disentangle the importance of the different factors affecting the allocation decisions of consumers. This is particularly relevant from a policy perspective, as the public policy implications of our study rely largely on the drivers of such behavior.

Overall, our paper speaks to the issue of financial decision making and financial mistakes in real world environments. In addition, this paper also adds to the so-called credit card puzzle and the literature on market implications of heuristics. Although the literature on these topics is still scarce, we hope that the results documented in this paper will generate further research. 


\section{Appendix}

In this appendix we derive a simple period-by-period cost minimization problem. To compute the minimum cost we divide the consumers optimization problem into two stages. In the first stage, for each period, consumers select the total amount of purchases and payments to be made with their credit cards on that month, and as a result, the total amount of debt to carry on. In the second stage, once individuals have selected the totals, they decide on the allocation of those purchases and repayments between the cards they already hold. Our model study only the second stage. Therefore, we take total payments and purchases as given and solve for the allocation that minimizes interest and fees costs.

We assume that rational consumers decide the allocation of payments and purchases between cards to minimize the expenditure on fees and interests. That is, for the two card case, we solve for the optimal purchases $\left(X_{i t}^{R}\right)$ and payments $\left(P_{i t}^{R}\right)$ in each card $(i=1,2)$ which solve the following cost minimization problem:

$$
\begin{gathered}
\mathcal{C}\left(P_{1 t}, P_{2 t}, X_{1 t}, X_{2 t}\right) \equiv \begin{array}{c}
\min _{P_{1 t}, P_{2 t}, X_{1 t}, X_{2 t}}\left\{C_{1 t} \cdot 1\left[P_{1 t}<P M i n_{i t}\right]+F_{1 t} \cdot 1\left[D_{1 t-1}-P_{1 t}+X_{1 t}>L_{1 t}\right]+\right. \\
{\left[D_{1 t-1}-P_{1 t}+X_{1 t}\right] \cdot 1\left[D_{1 t-1}>P_{1 t}\right] \cdot r_{1 t}+} \\
C_{2 t} \cdot 1\left[P_{2 t}<P M i n_{2 t}\right]+F_{2 t} \cdot 1\left[D_{2 t-1}-P_{2 t}+X_{2 t}>L_{2 t}\right]+ \\
\left.\left[D_{2 t-1}-P_{2 t}+X_{2 t}\right] \cdot 1\left[D_{2 t-1}>P_{2 t}\right] \cdot r_{2 t}\right\}
\end{array}
\end{gathered}
$$

subject to

$$
\begin{aligned}
& P T_{t}=P_{1 t}+P_{2 t} \\
& P_{1 t} \geq 0, P_{2 t} \geq 0 \\
& X T_{t}=X_{1 t}+X_{2 t} \\
& X_{1 t} \geq 0, X_{2 t} \geq 0 \\
& D_{1 t-1}-P_{1 t}+X_{1 t} \leq L_{1 t}, D_{2 t-1}-P_{2 t}+X_{2 t} \leq L_{2 t} \\
& r_{i t}, C_{i t}, F_{i t}, L_{i t}, P M i n_{i t}, X_{t}, D_{i t-1} \text { and } P_{t} \text { given for } \mathrm{i}=1,2 .
\end{aligned}
$$

where $P_{i t}$ is the payment made to card $i$ in period $t, X_{i t}$ are the monthly purchases made with card $i$ in period $t, P M i n_{i t}$ is the minimum monthly payment, $r_{i t}$ the monthly interest rate and $L_{i t}$ the credit limit. $C_{i t}$ is the late payment fee charged by the bank if the minimum monthly payment $P M i n_{i t}$ is not made during the billing cycle, $F_{i t}$ is the overlimit fee charged if the outstanding 
balance exceeds the credit limit $L_{i t}$ and $D_{i t}$ represents the outstanding balance at the end of the billing cycle. $1[\cdot]$ represents an indicator function.

The first line of the objective function corresponds to credit card 1. The first term represents the late payment fee $C_{i t}$ times an indicator variable that turns on when the payment to card 1 is less than the minimum payment ${ }^{19}$. The second term is the overlimit fee, $F_{i t}$ charged when the outstanding balance on card 1, including current payments and purchases, surpasses the credit limit. The third term corresponds to the interest rate paid. This expression is composed of three terms. The first one consists on the balance on which interests are charged. This balance is composed by the previous debt, minus the payments, plus the current purchases. Notice that, for debt revolvers, new purchases start accruing interests immediately. That is, wrong purchases allocations are costly regardless of the expectation about future payments when individuals hold debt in the more expensive card. The second term represents whether the individual pays the closing balance in full or not; if she does not do so, interests are accrued. The third term refers to the monthly interest rate of card 1 . The line for the credit card 2 is analogous.

This is a linear problem that involves corner solutions. In general, these corner solutions are going to be defined by the values of payments and/or purchases for which the indicator functions turn on. Because of the interactions between payments and purchases, we search for the optimal purchases and payments in a $\{$ Purchase, Payment $\}$ grid of $\$ 1$ dollar increments. We solve the model and derive the optimal purchases and payments for each card, period and consumer. Next, we use these allocations to estimate the optimal financing costs for each individual. With this at hand, we compare these costs with the actual financing costs faced by each cardholder and calculate the monetary costs of mistakes.

\footnotetext{
${ }^{19}$ Since we do not know the day the payment was made, we assume that they payment was within the grace period, thus we underestimate the cost of mistakes
} 


\section{References}

Agarwal, Sumit, John C. Driscoll, Xavier Gabaix, and David Laibson, "Learning in the Credit Card Market," Working Paper 13822, National Bureau of Economic Research February 2008.

_, Souphala Chomsisengphet, Chunlin Liu, and Nicholas S. Souleles, "Do Consumers Choose the Right Credit Contracts?," CFS Working Paper Series, 2005.

Ausubel, Lawrence M., "The Failure of Competition in the Credit Card Market," American Economic Review, March 1991, 81 (1), 50-81.

Avalos, Marcos and Fausto Hernandez, "Competencia Bancaria en Mexico," 2006. Serie Estudios y Perspectivas N 62 CEPAL.

Banxico, "Reporte sobre el Sistema Financiero," Technical Report, Banco de Mexico 2006.

Benartzi, Shlomo and Richard H. Thaler, "Naive Diversification Strategies in Defined Contribution Saving Plans," American Economic Review, March 2001, 91 (1), 79-98.

Bernheim, B. Douglas and Daniel M. Garrett, "The Effects of Financial Education in the Workplace: Evidence from a Survey of Households," Journal of Public Economics, August 2003, 87, $1487-1519$

Bertaut, Carol C. and Michael Haliassos, "Debt Revolvers for Self Control," University of Cyprus Working Papers in Economics 0208, University of Cyprus Department of Economics May 2001.

- and _, "Credit cards: Facts and theories," in G. Bertola, R. Disney, and C. Grant, eds., The Economics of Consumer Credit Demand and Supply, MIT Press 2006.

Bertrand, Marianne, Dean Karlin, Sendhil Mullainathan, Eldar Shafir, and Jonathan Zinman, "What's Psychology Worth? A Field Experiment in the Consumer Credit Market," NBER Working Papers 11892, National Bureau of Economic Research, Inc December 2005.

Campbell, John Y, "Household Finance," Journal of Finance, 2006, 61, 1553-1604.

DellaVigna, Stefano and Ulrike Malmendier, "Paying Not to Go to the Gym," American Economic Review, June 2006, 96 (3), 694-719.

Ellison, Glenn, "Bounded Rationality in Industrial Organization," in Whitney Newey Richard Burnell and Torsten Persson, eds., Advances in Economics and Econometrics: Theory and Applications, Cambridge University Press, forthcoming. 
Gross, David B. and Nicholas S. Souleles, "Do Liquidity Constraints and Interest Rates Matter for Consumer Behavior? Evidence from Credit Card Data," Quarterly Journal of Economics, February 2002, 117 (1), 149-185.

Miravete, Eugenio J., "Choosing the Wrong Calling Plan? Ignorance and Learning," American Economic Review, 2003, 93, 297-310.

Prelec, Drazen and George Loewenstein, "The Red and the Black: Mental Accounting of Savings and Debt," Marketing Science, 1998, 17, 4-28.

Ranyard, Rob, Lisa Hinkley, Janis Williamson, and Sandie McHugh, "The role of mental accounting in consumer credit decision processes," Journal of Economic Psychology, August 2006, $27(4), 571-588$.

Shui, Haiyan and Lawrence M. Ausubel, "Time Inconsistency in the Credit Card Market," January 2005, (176).

Thaler, Richard, "Mental Accounting and Consumer Choice," Marketing Science, 1985, 4, 199-214.

_, "Mental Accounting Matters," Journal of Behavioral Decision Making, 1999, 12, 183-206.

Zinman, Jonathan, "Household Borrowing High and Lending Low Under No-Arbitrage," April 2007. Dartmouth College Working Paper. 


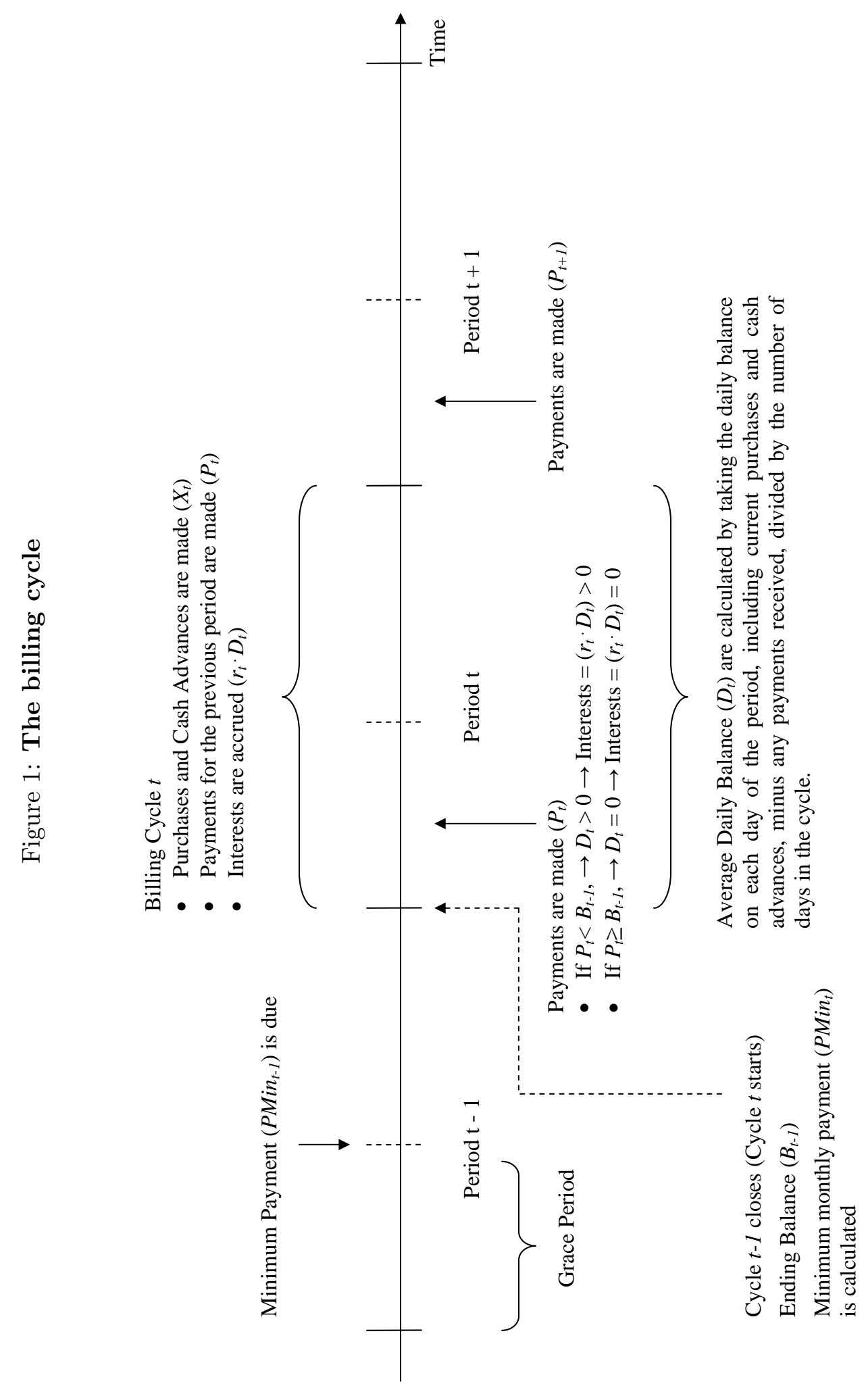


Figure 2: Monthly interest rate differential across credit cards

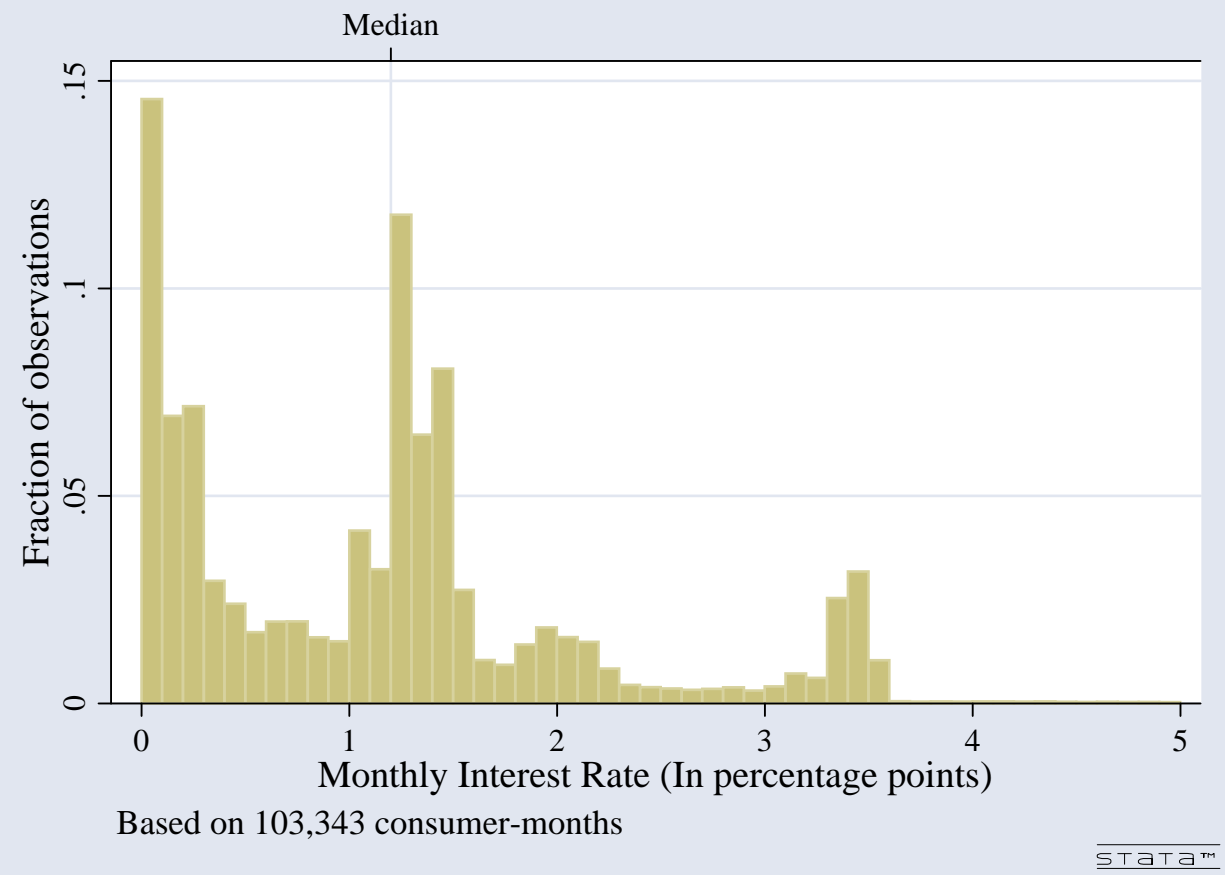

Figure 3: Allocation of Interest Paying Debt

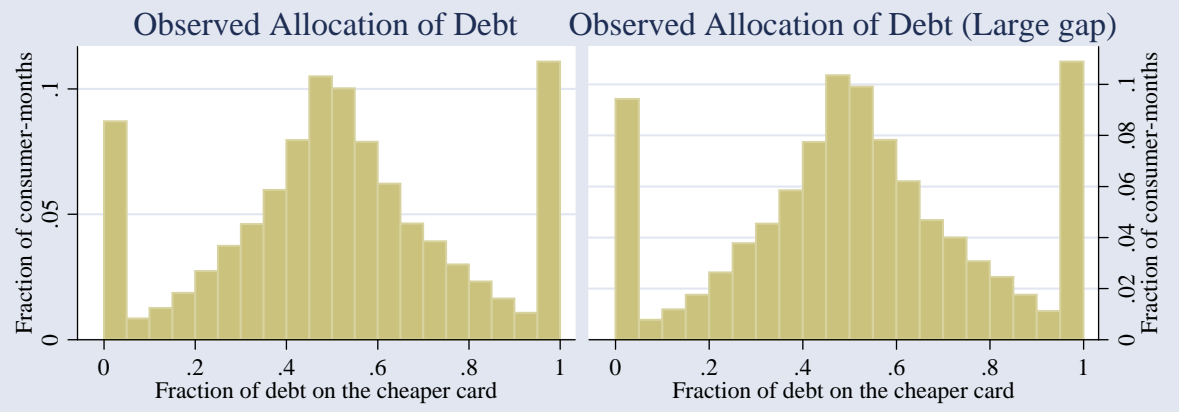

Optimal Allocation of Debt

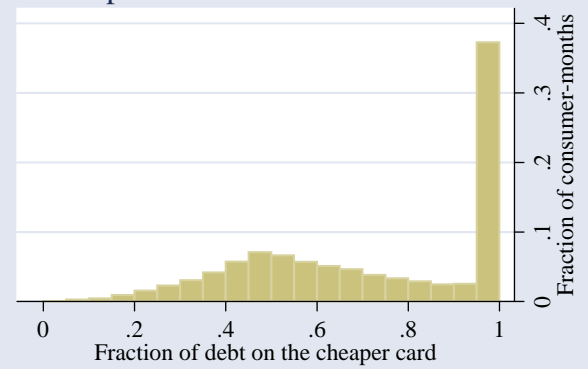

Based on 103,343 consumer-months (10,335 consumers). 
Figure 4: Share of Monthly Payments to the Expensive Cards

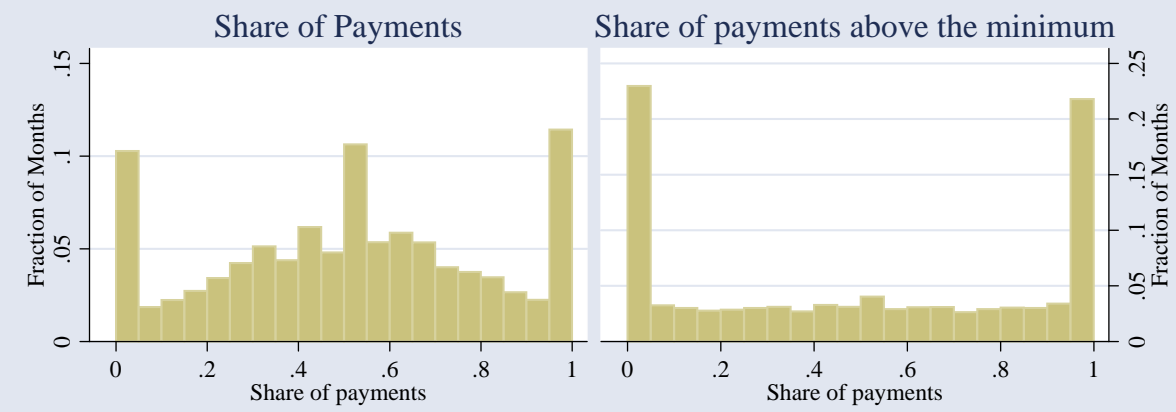

Share of payments above the minimum

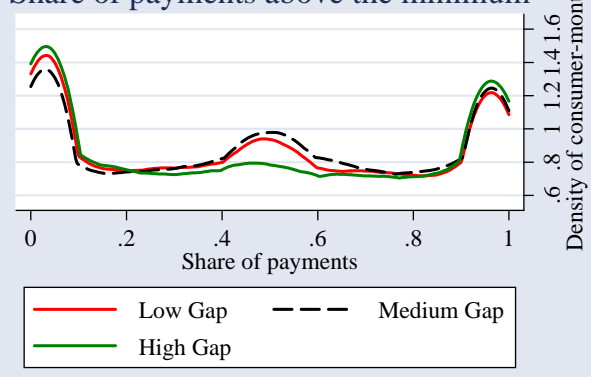

Based on 84,582 consumer-months.

Figure 5: Share of Monthly Purchases to the Expensive Cards
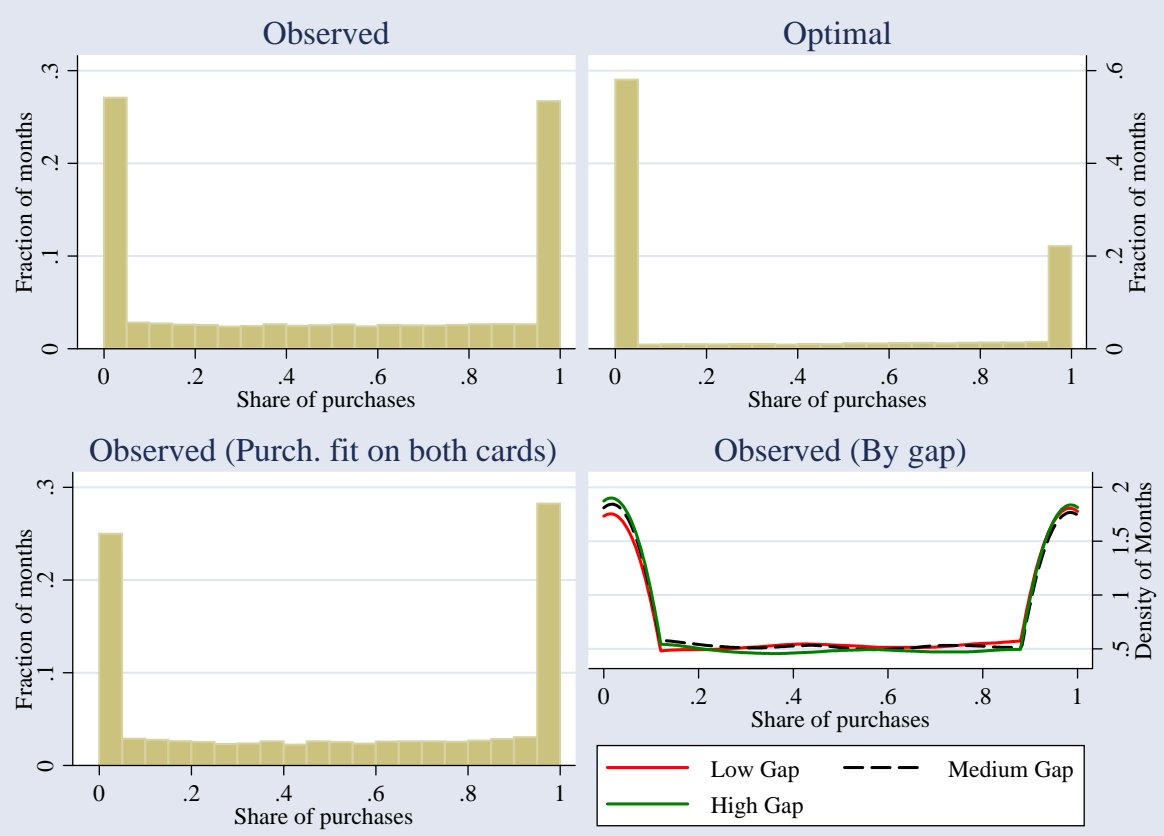

Based on 45,435 consumer-months. 
Figure 6: Possible allocation of payments

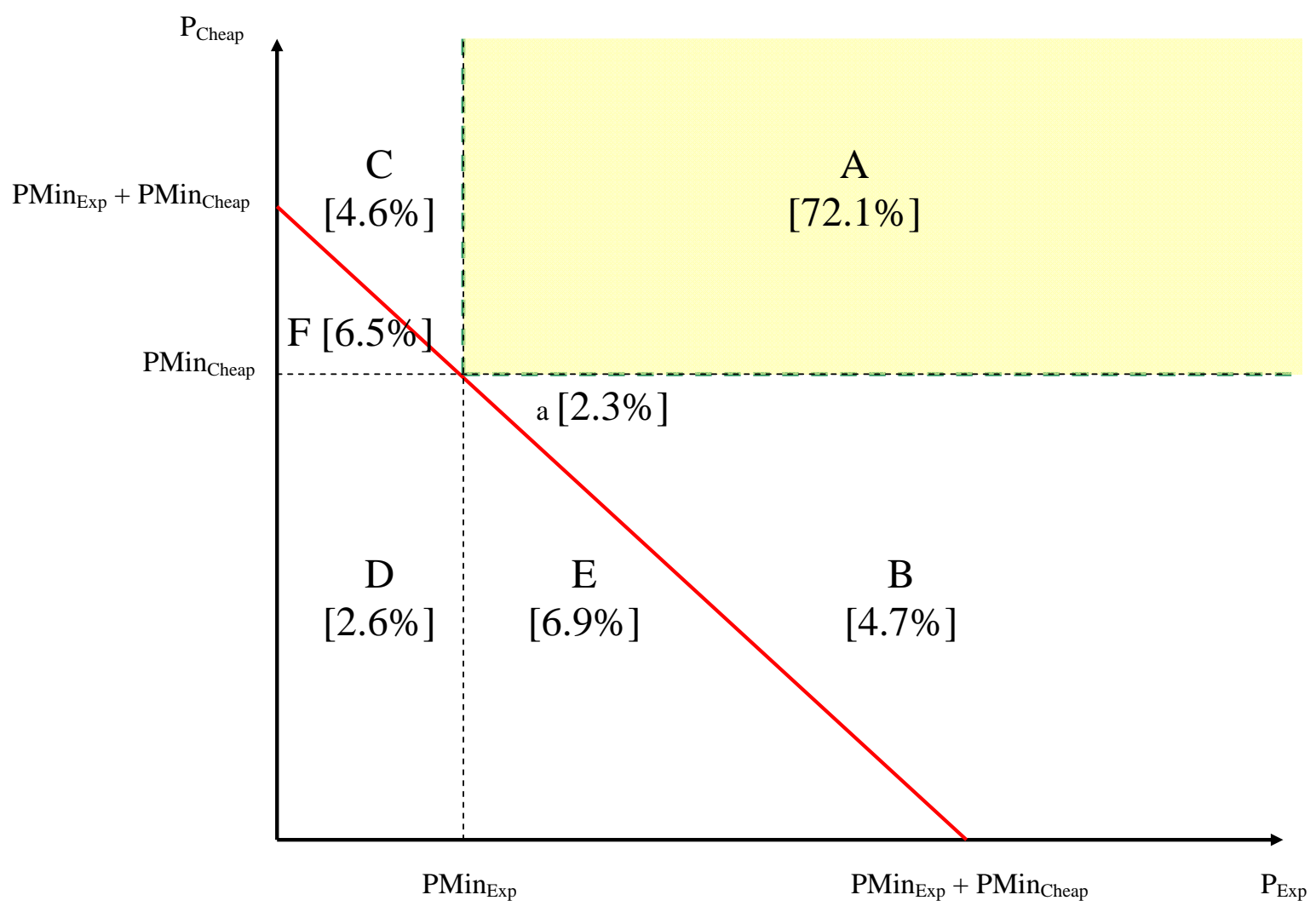


Figure 7: Possible allocation of purchases

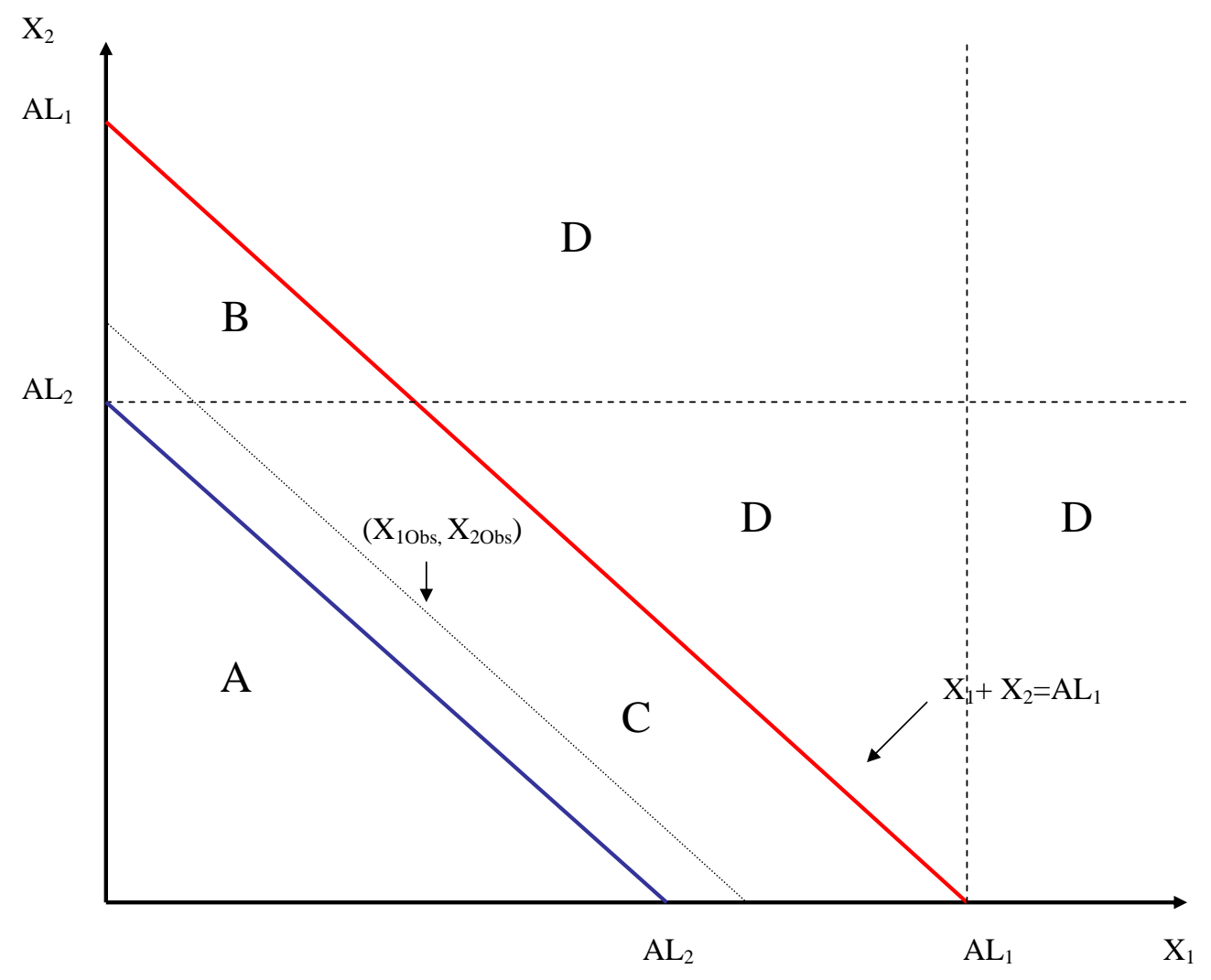


Figure 8: Fraction of time consumers pay extra interest or extra fees

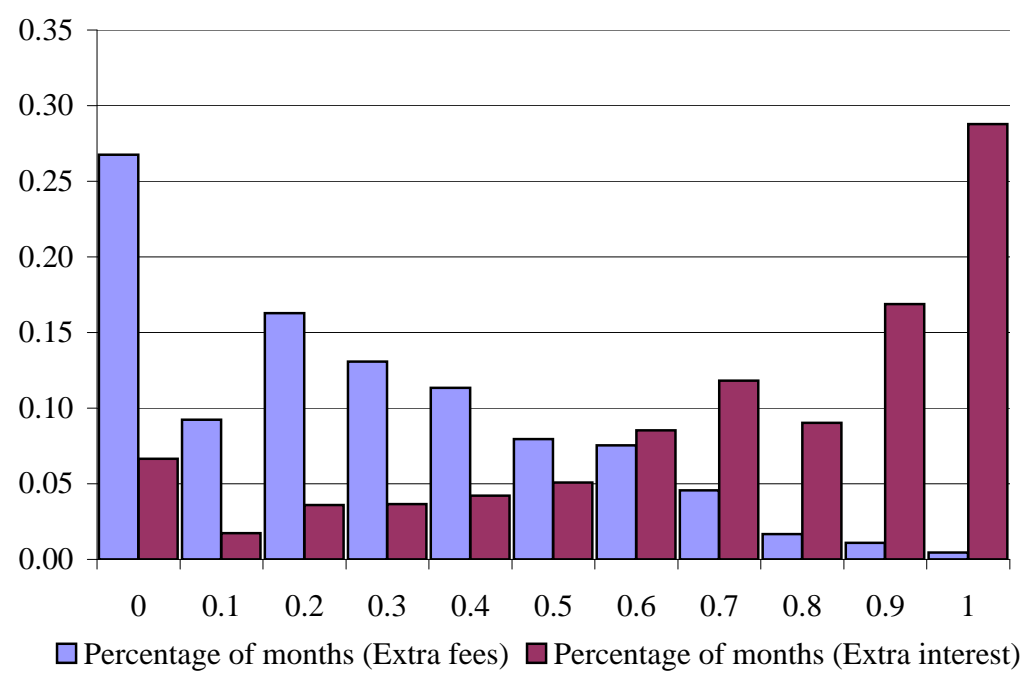

Figure 9: Average misallocation cost in pesos

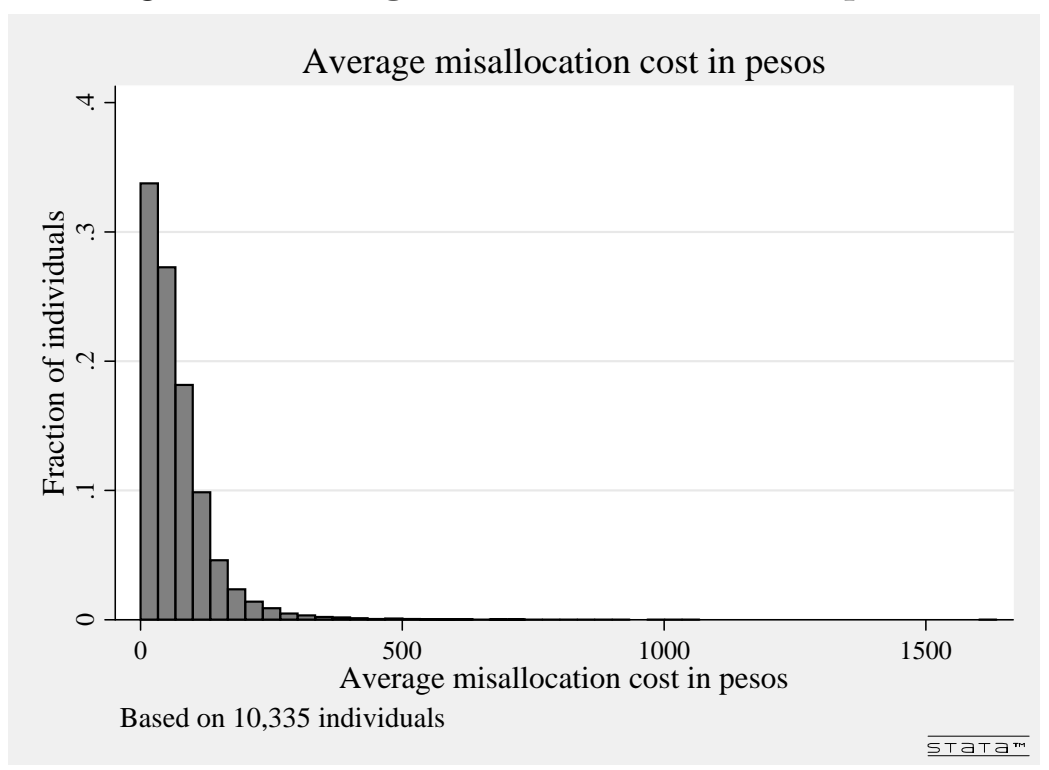


Figure 10: Total misallocation cost as a fraction of total financing cost

Total misallocation cost as a fraction of the total financing cost

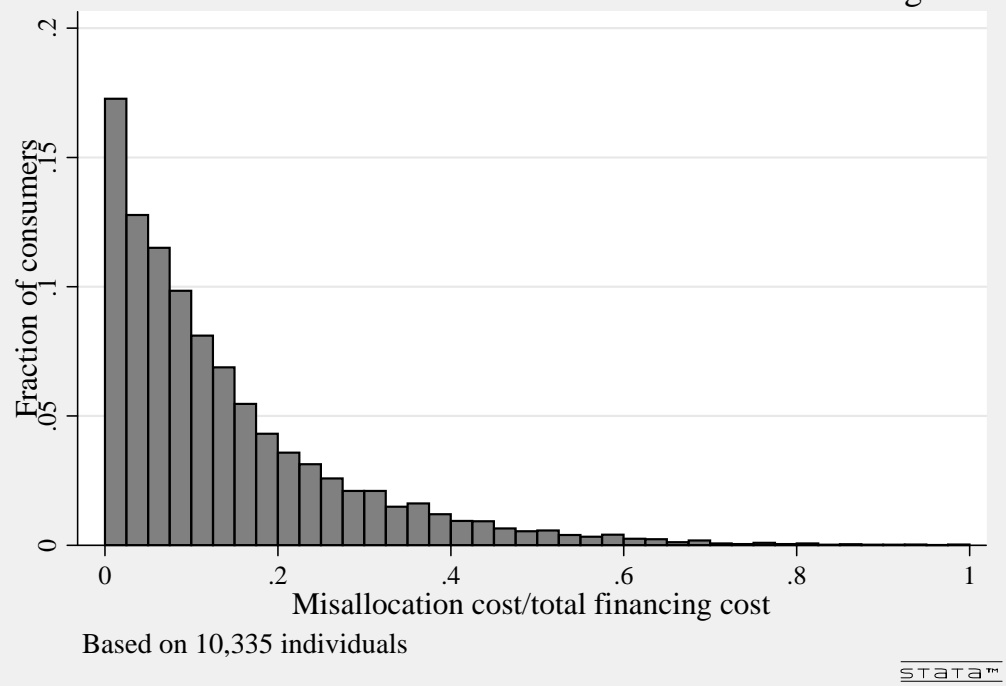

Figure 11: Average misallocation cost by decile and source

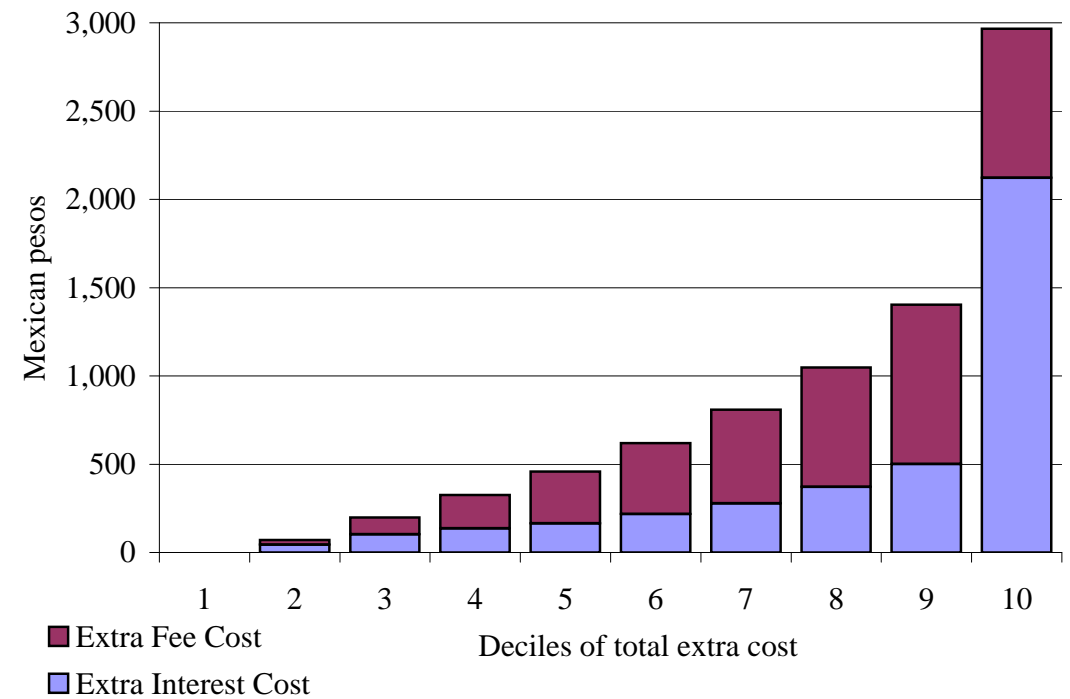




\section{Table 1: Summary statistics for consumers with two comparable credit cards}

The following table summarizes the mean of consumers' monthly flows and stocks for their combined credit cards. In Panel $\mathrm{A}$ an observation is a consumer-month; in Panel B and Panel C, the unit of analysis is a consumer. Figures are in Mexican Pesos. The raw sample includes 114,720 consumer-months. Once we consider only the periods in which debt is positive, the sample reduces to 103,343 consumer-months and 10,335 consumers. The statistics in Panel B are based only on the non-missing observations. The utilization rate was calculated as total debt over total credit limit. Standard errors are in parenthesis. In Panel C, the number of observations are in parenthesis.

\begin{tabular}{|c|c|c|}
\hline & $\begin{array}{c}\text { Raw } \\
(1)\end{array}$ & $\begin{array}{c}\text { Given }>0 \\
(2)\end{array}$ \\
\hline \multicolumn{3}{|l|}{ Panel A: Monthly Statistics } \\
\hline Interest paying debt & $\begin{array}{c}22,136 \\
(25,826)\end{array}$ & $\begin{array}{c}24,573 \\
(26,087)\end{array}$ \\
\hline Credit Limit & $\begin{array}{c}50,351 \\
(51,411)\end{array}$ & - \\
\hline Purchases and cash advances & $\begin{array}{c}3,685 \\
(6,987)\end{array}$ & $\begin{array}{l}4,749 \\
(7,607)\end{array}$ \\
\hline Payments & $\begin{array}{c}4,185 \\
(6,159)\end{array}$ & $\begin{array}{c}4,465 \\
(6,263)\end{array}$ \\
\hline Fees & $\begin{array}{c}108 \\
(168)\end{array}$ & $\begin{array}{c}257 \\
(169)\end{array}$ \\
\hline Percentage of months paying fees & $\begin{array}{c}42 \\
(49)\end{array}$ & - \\
\hline Percentage of months paying interests & $\begin{array}{c}90 \\
(30)\end{array}$ & - \\
\hline Percentage of months borrowing in both cards & $\begin{array}{l}73 \\
(44)\end{array}$ & $\begin{array}{c}82 \\
(38)\end{array}$ \\
\hline Average Utilization Rate & $\begin{array}{c}61 \\
(40)\end{array}$ & $\begin{array}{c}65 \\
(37)\end{array}$ \\
\hline Debt weighted monthly interest rate & $\begin{array}{l}2.54 \\
(0.9)\end{array}$ & - \\
\hline \multicolumn{3}{|c|}{ Panel B: Statistics by consumer (Percentage of consumers) } \\
\hline Incur fees at least one month & 81 & - \\
\hline Incur interests at least one month & 97 & - \\
\hline Incur interests at least half the time & 90 & - \\
\hline Borrow in both cards at least half of the time & 74 & - \\
\hline \multicolumn{3}{|l|}{ Panel C: Demographics } \\
\hline Monthly Income (Median) & $\begin{array}{l}10,000 \\
(5,012)\end{array}$ & - \\
\hline Male & $\begin{array}{c}0.61 \\
(7,748)\end{array}$ & - \\
\hline Age & $\begin{array}{c}44 \\
(4,999)\end{array}$ & - \\
\hline Avg. years of tenure with a credit card & $\begin{array}{c}8 \\
(10,335)\end{array}$ & - \\
\hline
\end{tabular}




\section{Table 2: Percentage of observations in which individuals make allocation mistakes}

The following table presents the percentage of observations in which individuals make allocation mistakes. The rows show the percentage of observations in which individuals pay less, equal or more interest relative to the optimal allocation. Similarly, the columns correspond to the percentage of observations in which consumers pay less, equal or more fees compared with the optimum. The table is based on 103,343 consumer-months.

\begin{tabular}{ccccc}
\hline \hline & & \multicolumn{3}{c}{ Fees } \\
& & Less or Equal & More & Total \\
\hline \multirow{3}{*}{ Interest } & Less & $0 \%$ & $8 \%$ & $8 \%$ \\
& Equal & $16 \%$ & $1 \%$ & $17 \%$ \\
& More & $58 \%$ & $16 \%$ & $74 \%$ \\
& & & & \\
& Total & $74 \%$ & $26 \%$ & $100 \%$ \\
\hline \hline
\end{tabular}




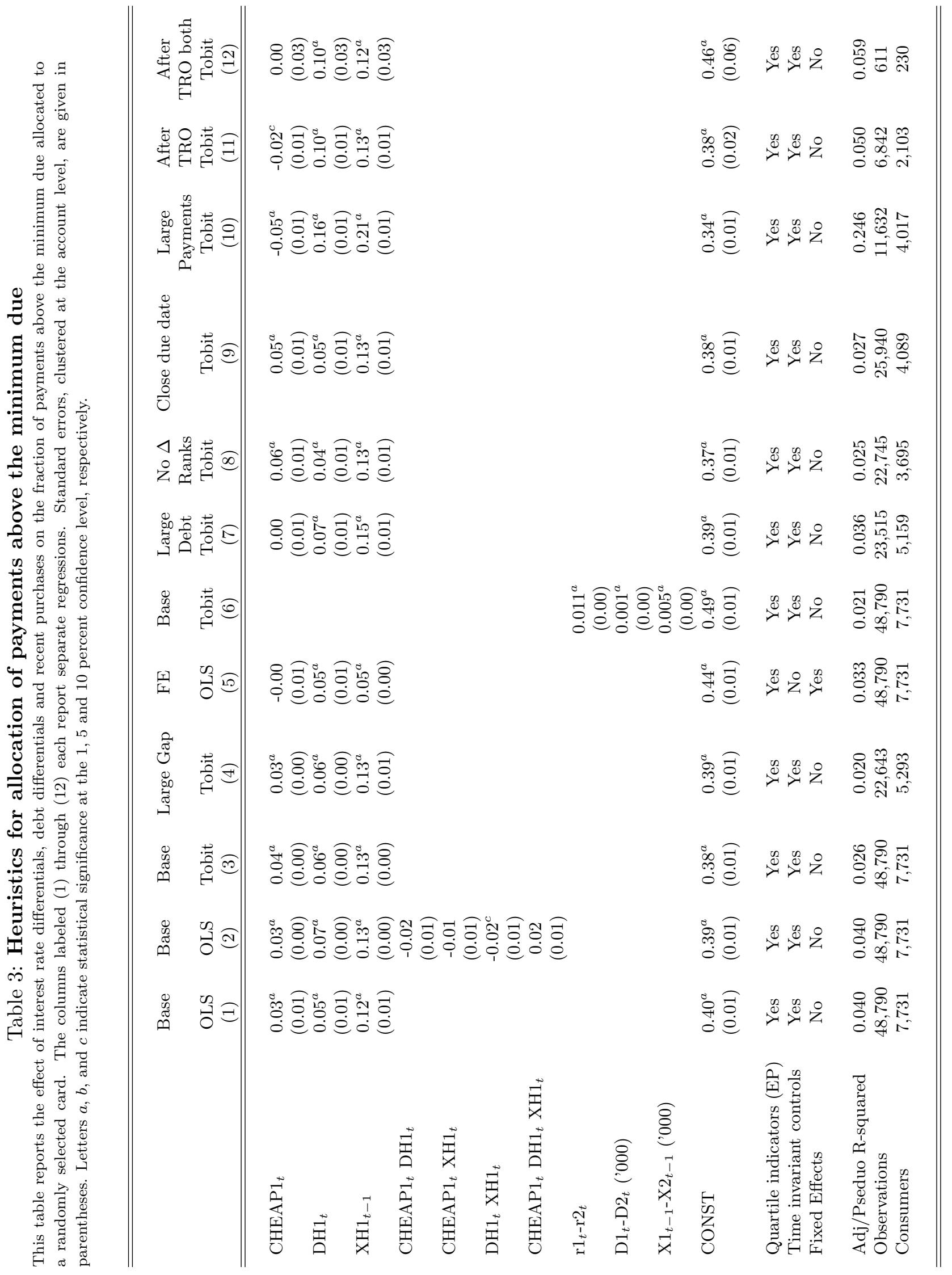




\section{Table 4: Heuristics for allocation of the minimum payment due}

The following table presents the effect of interest rates, debt differentials and previous purchases on the probability of making the minimum payment due. The sample includes only observations in which individuals miss the minimum payment on one card despite it was feasible for them not to do so. Standard errors, clustered at the account level, are given in parentheses. Letters $a, b$, and $c$ indicate statistical significance at the 1,5 and 10 percent confidence level, respectively.

\begin{tabular}{lccc}
\hline \hline & & & \\
& Baseline & Large Gap & Close due date \\
& Probit & Probit & Probit \\
& $(1)$ & $(2)$ & $(3)$ \\
\hline & & & \\
CHEAP1 $1_{t}$ & 0.02 & 0.03 & $0.04^{c}$ \\
& $(0.01)$ & $(0.02)$ & $(0.02)$ \\
DH1 $1_{t}$ & $0.19^{a}$ & $0.20^{a}$ & $0.18^{a}$ \\
& $(0.01)$ & $(0.02)$ & $(0.02)$ \\
XH1 $1_{t-1}$ & $0.31^{a}$ & $0.28^{a}$ & $0.33^{a}$ \\
& $(0.01)$ & $(0.02)$ & $(0.02)$ \\
Adj/Pseduo R-squared & 0.104 & 0.094 & 0.110 \\
Observations & 6,110 & 3,157 & 3,052 \\
Consumers & 3,508 & 2,066 & 1,764 \\
& & & \\
\hline \hline
\end{tabular}




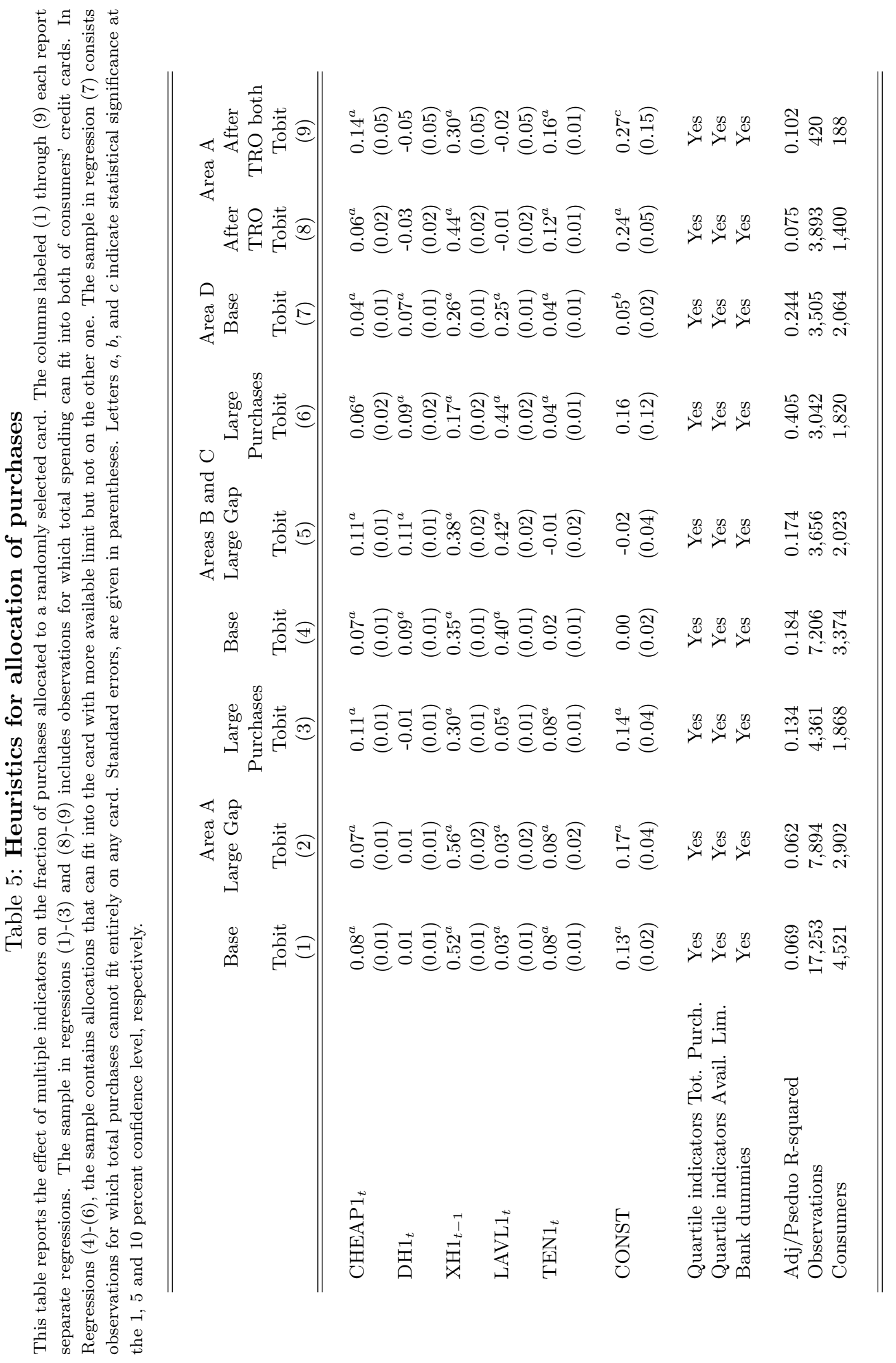




\section{Table 6: Response to teaser rate offers}

This table reports the response to teaser rate offers. Each column corresponds to a different dependent variable. Standard errors clustered at the consumer level, are given in parentheses. Letters $a, b$, and $c$ indicate statistical significance at the 1,5 and 10 percent confidence level, respectively.

\begin{tabular}{|c|c|c|c|c|}
\hline & $\begin{array}{l}\Delta \operatorname{Debt}_{t} \\
\text { OLS } \\
(1) \\
\end{array}$ & $\begin{array}{c}\Delta \text { Purchases }_{t} \\
\text { OLS } \\
(2) \\
\end{array}$ & $\begin{array}{c}\Delta \text { Payments }_{t} \\
\text { OLS } \\
(3) \\
\end{array}$ & $\begin{array}{c}\Delta \operatorname{Debt}_{t} \\
\text { OLS } \\
(4) \\
\end{array}$ \\
\hline $\mathrm{TR} 1 \mathrm{M} 1_{t+2}$ & $\begin{array}{c}12 \\
(209)\end{array}$ & $\begin{array}{c}82 \\
(281)\end{array}$ & $\begin{array}{c}45 \\
(238)\end{array}$ & $\begin{array}{l}-258 \\
(240)\end{array}$ \\
\hline $\mathrm{TR} 1 \mathrm{M} 1_{t+1}$ & $\begin{array}{l}352^{b} \\
(162)\end{array}$ & $\begin{array}{c}1,158^{a} \\
(340)\end{array}$ & $\begin{array}{c}200 \\
(229)\end{array}$ & $\begin{array}{c}166 \\
(203)\end{array}$ \\
\hline $\mathrm{TR} 1 \mathrm{M} 1_{t}$ & $\begin{array}{r}1,935^{a} \\
(226)\end{array}$ & $\begin{array}{l}-288 \\
(349)\end{array}$ & $\begin{array}{l}857^{a} \\
(248)\end{array}$ & $\begin{array}{c}66 \\
(197)\end{array}$ \\
\hline $\mathrm{TR} 1 \mathrm{M} 1_{t-1}$ & $\begin{array}{r}-1,653^{a} \\
(279)\end{array}$ & $\begin{array}{r}-1,315^{a} \\
(300)\end{array}$ & $\begin{array}{c}100 \\
(309)\end{array}$ & $\begin{array}{l}-132 \\
(182)\end{array}$ \\
\hline $\mathrm{TR} 1 \mathrm{M} 1_{t-2}$ & $\begin{array}{l}-123 \\
(192)\end{array}$ & $\begin{array}{c}364 \\
(343)\end{array}$ & $\begin{array}{c}-1,187^{a} \\
(263)\end{array}$ & $\begin{array}{c}2 \\
(197)\end{array}$ \\
\hline $\mathrm{TR} 3 \mathrm{M} 1_{t+2}$ & $\begin{array}{c}210 \\
(194)\end{array}$ & $\begin{array}{c}55 \\
(309)\end{array}$ & $\begin{array}{l}-270 \\
(287)\end{array}$ & $\begin{array}{l}-232 \\
(286)\end{array}$ \\
\hline $\mathrm{TR} 3 \mathrm{M} 1_{t+1}$ & $\begin{array}{c}1,020^{a} \\
(237)\end{array}$ & $\begin{array}{c}2,217^{a} \\
(317)\end{array}$ & $\begin{array}{l}-422^{c} \\
(232)\end{array}$ & $\begin{array}{l}-143 \\
(263)\end{array}$ \\
\hline $\mathrm{TR} \mathrm{M} 1_{t}$ & $\begin{array}{r}2,064^{a} \\
(207)\end{array}$ & $\begin{array}{c}-1,328^{a} \\
(375)\end{array}$ & $\begin{array}{c}13 \\
(210)\end{array}$ & $\begin{array}{l}-103 \\
(225)\end{array}$ \\
\hline $\mathrm{TR} 3 \mathrm{M} 2_{t}$ & $\begin{array}{r}1,082^{a} \\
(189)\end{array}$ & $\begin{array}{c}-24 \\
(306)\end{array}$ & $\begin{array}{c}-42 \\
(180)\end{array}$ & $\begin{array}{c}96 \\
(244)\end{array}$ \\
\hline $\mathrm{TR}_{3 \mathrm{M}} 3_{t}$ & $\begin{array}{c}1,252^{a} \\
(217)\end{array}$ & $\begin{array}{c}146 \\
(428)\end{array}$ & $\begin{array}{l}-162 \\
(171)\end{array}$ & $\begin{array}{c}236 \\
(458)\end{array}$ \\
\hline $\mathrm{TR} 3 \mathrm{M} 3_{t-1}$ & $\begin{array}{c}184 \\
(245)\end{array}$ & $\begin{array}{l}-609 \\
(417)\end{array}$ & $\begin{array}{l}510^{b} \\
(226)\end{array}$ & $\begin{array}{c}-5 \\
(227)\end{array}$ \\
\hline $\mathrm{TR} 3 \mathrm{M} 3_{t-2}$ & $\begin{array}{c}397 \\
(353)\end{array}$ & $\begin{array}{c}810 \\
(541)\end{array}$ & $\begin{array}{l}643^{c} \\
(383)\end{array}$ & $\begin{array}{l}-444 \\
(405)\end{array}$ \\
\hline $\begin{array}{l}\text { Int. Rate Offers and its lags } \\
\Delta \text { Limit and its lags } \\
\text { Time indicators } \\
\text { Fixed Effects }\end{array}$ & $\begin{array}{l}\text { Yes } \\
\text { Yes } \\
\text { Yes }\end{array}$ & $\begin{array}{l}\text { Yes } \\
\text { Yes } \\
\text { Yes }\end{array}$ & $\begin{array}{l}\text { Yes } \\
\text { Yes } \\
\text { Yes }\end{array}$ & $\begin{array}{l}\text { Yes } \\
\text { Yes } \\
\text { Yes }\end{array}$ \\
\hline $\begin{array}{l}\text { Adj/Pseduo R-squared } \\
\text { Observations } \\
\text { Consumers }\end{array}$ & $\begin{array}{c}0.007 \\
97,905 \\
10,335\end{array}$ & $\begin{array}{c}0.001 \\
97,905 \\
10,335\end{array}$ & $\begin{array}{c}0.003 \\
97,905 \\
10,335\end{array}$ & $\begin{array}{c}0.002 \\
97,905 \\
10,335\end{array}$ \\
\hline
\end{tabular}

